\title{
Unravelling consensus genomic regions conferring leaf rust resistance in wheat via meta-QTL analysis
}

\author{
Aduragbemi Amo $^{1}$ | Jose Miguel Soriano ${ }^{2}$ (
}

\author{
${ }^{1}$ State Key Laboratory of Crop Stress \\ Biology for Arid Areas, College of \\ Agronomy, Northwest A\&F Univ., \\ Yangling, Shaanxi, China \\ ${ }^{2}$ Sustainable Field Crops Programme, \\ Institute for Food and Agricultural Research \\ and Technology (IRTA), Lleida 25198, \\ Spain
}

\section{Correspondence}

Jose Miguel Soriano, Sustainable Field Crops Programme, Institute for Food and Agricultural Research and Technology (IRTA), 25198 Lleida, Spain.

Email: josemiguel.soriano@irta.cat

Assigned to Associate Editor Mark Sorrells.

\section{Funding information}

Ministerio de Ciencia e Innovación, Grant/Award Number: PID2019-109089RBC31

\begin{abstract}
Leaf rust, caused by the fungus Puccinia triticina Erikss (Pt), is a destructive disease affecting wheat (Triticum aestivum L.) and a threat to food security. Developing resistant cultivars represents a useful method of disease control, and thus, understanding the genetic basis for leaf rust resistance is required. To this end, a comprehensive bibliographic search for leaf rust resistance quantitative trait loci (QTL) was performed, and 393 QTL were collected from 50 QTL mapping studies. Afterward, a consensus map with a total length of $4,567 \mathrm{cM}$ consisting of different types of markers (simple sequence repeat [SSR], diversity arrays technology [DArT], chip-based single-nucleotide polymorphism [SNP] markers, and SNP markers from genotypingby-sequencing) was used for QTL projection, and meta-QTL (MQTL) analysis was performed on 320 QTL. A total of 75 MQTL were discovered and refined to 15 highconfidence MQTL (hcmQTL). The candidate genes discovered within the hcmQTL interval were then checked for differential expression using data from three transcriptome studies, resulting in 92 differentially expressed genes (DEGs). The expression of these genes in various leaf tissues during wheat development was explored. This study provides insight into leaf rust resistance in wheat and thereby provides an avenue for developing resistant cultivars by incorporating the most important hcmQTL.
\end{abstract}

\footnotetext{
Abbreviations: AIC, Akaike information criterion; AUDPC, area under the disease progress curve; CI, confidence interval; DArT, diversity arrays technology; DEG, differentially expressed gene; DS, disease severity; EA+, early aborted colonies, without plant cell necrosis; EA-, early aborted colonies, associated with plant cell necrosis; EST+, established colonies, without plant cell necrosis; EST-, established colonies, associated with plant cell necrosis; GO, gene ontology; hcmQTL, high-confidence MQTL; $\mathrm{HR}$, host reaction; IE, infection efficiency; IR, infection rate; IT, infection type; LIA, leaf infected area; LP, latent period; LR, leaf rust resistance; LS, lesion size; LTN, leaf tip necrosis; MAS, marker-assisted selection; MDS, maximum disease severity; MQTL, meta-quantitative trait loci; NEC, all necrotic colonies; PVE, phenotypic variation explained; RLK, receptor-like kinase; SNP, single-nucleotide polymorphism; SPL, spore production per lesion; SPS, spore production per unit of sporulating tissue; SSR, simple sequence repeat.
}

\section{1 | INTRODUCTION}

Leaf rust, caused by the fungal pathogen Puccinia triticina Erikss $(\mathrm{Pt})$, causes a significant reduction in grain yield worldwide, and thus, it is considered a disease with significant importance in wheat (Triticum aestivum L.) (Khan et al., 2013; Kolmer, 2005). Compared with other fungal rust diseases, such as stem and stripe rust, leaf rust occurs more frequently and has a wider distribution (Bolton et al., 2008). This wide spread of leaf rust may be because the spores of $P$. triticina are transported long distances via wind or humans, thereby causing damage to wheat crops outside their environment or country of origin, as has been observed in various studies in 
North America (Bolton et al., 2008; Kolmer, 2005; Brown \& Hovmøller, 2002). The most economical, efficient, environmentally sustainable, and socially acceptable way to manage rust disease globally is to grow rust-resistant cultivars (McIntosh et al., 1995; Wiesner-Hanks \& Nelson, 2016). Therefore, to understand how best to combine genes and effectively carry out marker-assisted selection (MAS), mapping the target genes conferring resistance in existing parental stocks is essential (Kuchel et al., 2007).

Quantitative trait loci (QTL) mapping is an effective analytical method for studying and manipulating complex traits in crops (Doerge, 2002; Xin et al., 2020). However, QTL mapping has several limitations based on the type of markers, the influence of the environment, the use of different parents, and the size of mapping populations. Therefore, little progress has been made regarding fine mapping and QTL cloning in wheat because of the paucity of high-resolution linkage maps, as the use of simple sequence repeat (SSR) markers is constrained by their inability to saturate the wheat genome (Somers et al., 2004). Consequently, QTL are frequently present in large genomic regions, and MAS is restricted to small numbers of validated markers (Wang et al., 2015). In recent years, a revolution in the QTL analysis of complex traits has occurred via the introduction of different high-throughput sequencing and genotyping technologies, thus aiding genetic map construction and marker development (Wang et al., 2018). Numerous QTL studies have been performed in wheat; however, the detected QTL often do not overlap either in part or in whole because of a different combination of parental lines or studies in multiple environments (Rong et al., 2007). Therefore, there is a need to detect the most promising consensus QTL found among studies using different parents that is stable across environments.

Furthermore, recognizing robust and reliable QTL and refining their intervals can be achieved by meta-QTL (MQTL) analysis without using expensive resources (Goffinet \& Gerber, 2000). The free software BioMercator (Arcade et al., 2004), used for MQTL analysis, allows the compilation of a vast number of genetic maps from various sources and can project QTL to a consensus or reference map (Veyrieras et al., 2007). Thus, MQTL analysis could identify the consensus QTL associated with the trait in multiple environments and genetic backgrounds (Goffinet \& Gerber, 2000). Quantitative trait loci for similar traits may be combined synergistically into MQTL traits by a single MQTL analysis. The reported MQTL method can be used for MAS (Maccaferri et al., 2015; Yu et al., 2014).

Several studies on MQTL analysis for disease resistance in wheat have been carried out successfully, including those for tan spot resistance (Liu et al., 2020), Fusarium head blight resistance (Liu et al., 2009; Löffler et al., 2009; Venske et al., 2019; Zheng et al., 2020), leaf rust resistance (Soriano \& Royo, 2015), and stem rust resistance (Yu et al., 2014). The

\section{Core Ideas}

- Meta-QTL (MQTL) analysis is an effective approach to synthesize QTL information.

- MQTL analysis reduced the confidence intervals for leaf rust resistance.

- MQTL allowed the identification of candidate genes.

first MQTL analysis on leaf rust focused only on identifying consensus genomic regions for the trait. In addition, the authors did not use single-nucleotide polymorphism (SNP)based genetic maps because of the lack of QTL studies in leaf rust using high-throughput SNP arrays several years ago. However, in this study, we aimed to delve deeper into the genetic architecture underlying leaf rust disease by discovering putative candidate genes from the newly released wheat genome sequence (The International Wheat Genome Sequencing Consortium et al., 2018), incorporating transcriptomic studies, and studying the function of these in genes in different tissues.

\section{2 | MATERIALS AND METHODS}

\section{1 | Bibliographic search for wheat leaf rust resistant QTL}

Using Google Scholar (https://scholar.google.com/) and the Web of Science (http://www.webofknowledge.com/), an exhaustive search for publications containing QTL conferring leaf rust resistance in wheat was performed. For each study, the information collected during the QTL compilation included the following: (a) the mapping population type of $\mathrm{F}_{2: 3}$, recombinant inbred lines and double haploids; (b) 19 disease resistance traits including disease severity (DS), area under the disease progress curve (AUDPC), leaf infected area (LIA), infection type (IT), infection rate (IR), leaf rust resistance (LR), leaf tip necrosis (LTN), latent period (LP), spore production per unit of sporulating tissue (SPS), spore production per lesion (SPL), infection efficiency (IE), lesion size (LS), early aborted colonies, associated with plant cell necrosis (EA-), early aborted colonies, without plant cell necrosis $(\mathrm{EA}+)$, established colonies, associated with plant cell necrosis (EST-), established colonies, without plant cell necrosis (EST+), all necrotic colonies (NEC), maximum disease severity (MDS), and host reaction (HR); (c) the number of lines in the mapping population; (d) the logarithm of the odds score; (e) the $R^{2}$ value, which denotes the percentage of the phenotypic variation explained (PVE); and (f) the markers flanking the QTL position (Supplemental Table S1). 


\subsection{QTL projection on the consensus map}

To project the largest number of QTL, the high-density consensus map developed by Venske et al. (2019) was used. This consensus map incorporated three marker types: SNP, diversity array technology [DArT], and SSR markers. The SNPs were sourced from chip-based markers and genotype-by-sequencing (Cavanagh et al., 2013; Saintenac et al., 2013; Wang et al., 2014). The SSR markers, including functional markers, were provided from three genetic maps (Wheat, Consensus SSR 2004, Wheat Composite 2004, and Wheat Synthetic $\times$ Opata) obtained from the GrainGenes database (https://wheat.pw.usda.gov/GG3/). Wheat consensus map version 4.0, which contains more than 100,000 DArT sequencing markers and nearly 4,000 DArT markers developed from over 100 genetic maps, was downloaded from https://www.diversityarrays.com/technologyand-resources/genetic-maps. The initial QTL were projected following the approach described in Chardon et al. (2004) using BioMercator v4.2 software (Arcade et al., 2004) (https://urgi.versailles.inra.fr/Tools/BioMercator-V4). Before projecting onto the consensus map, a confidence interval (CI) of $95 \%$ was homogenized across the different studies using the following formulas: $530 /(N \times \mathrm{PVE})$ for $\mathrm{F}_{2: 3}$, $163 /(N \times \mathrm{PVE})$ for recombinant inbred lines, and $287 /(N \times$ PVE) for double haploids (Darvasi \& Soller, 1997; Guo et al., 2006), where $N$ is the number of genotypes in the mapping population, and PVE is the phenotypic variance explained by the QTL.

\section{3 | MQTL analysis and validation using genome-wide association studies}

The MQTL analysis was conducted using the software BioMercator (Arcade et al., 2004; Sosnowski et al., 2012) by incorporating two approaches for the analysis. The first approach, proposed by Goffinet and Gerber (2000), is used when the QTL count for a chromosome is $<10$. The second approach, proposed by Veyrieras et al. (2007), is used when the QTL count for a chromosome is above $>10$. For the first approach, the lowest Akaike information criterion (AIC) value was selected as the best fit model. However, the best model was selected from the AIC, AICc, AIC3, Bayesian information criterion, and average evidence weight models from the second approach. Therefore, the model with the lowest criteria in at least three of the models was selected and regarded as the best fit model. The sequences of the flanking markers of each MQTL were submitted to BLAST analysis against the Chinese Spring reference genome (https:// wheat.pw.usda.gov/blast) (The International Wheat Genome Sequencing Consortium et al., 2018), and their corresponding physical positions were identified. In addition, the MQTL found in this study were validated using recent association studies with different genetic backgrounds and environments aimed at identifying loci and QTL related to leaf rust resistance in wheat.

\subsection{Establishment of hemQTL and candidate gene mining}

To further refine the MQTL, those with at least five overlapping QTL having a physical distance $<20 \mathrm{Mb}$ and a genetic distance $<10 \mathrm{cM}$ were selected and called highconfidence MQTL (hcmQTL). The annotated reliable genes (HighConfidenceGenes v1.1) within the interval of each hcmQTL were obtained, and their functional annotations were examined (https://wheat-urgi.versailles.inra.fr/SeqRepository/Annotations).

\section{5 | Expression of candidate genes within hcmQTL intervals}

To check for the candidate genes that were differentially expressed within the hcmQTL intervals, three expression datasets, NCBI-ID ERP013983, SRP041017, and ERP009837 (Dobón et al., 2016; Rudd et al., 2015; Zhang et al., 2014) were used based on experiments reported at ExpVIP (http://www.wheat-expression.com) (Borrill et al. et al., 2016). The ERP013983 dataset consists of differential expression data of wheat resistance cultivar Avocet inoculated with a PST 87/66 strain, with leaf samples collected at $0,1,2,3$, and $5 \mathrm{~d}$ postinoculation. In the second dataset, SRP041017, the transcriptome of the hexaploid wheat line N9134 inoculated with the Chinese Pst race CYR 31 was compared with the same line inoculated with powdery mildew (Blumeria graminis f. sp. tritici) race E09 at 1, 2, and $3 \mathrm{~d}$ postinoculation. The third dataset, ERP009837, consists of differential expression data of the wheat cultivar Riband inoculated with the fungus Zymoseptoria tritici (Septoria tritici blotch), and the expression data were collected at 1, 4, 9, 14, and $21 \mathrm{~d}$ postinoculation. The count data of all the expression data were further analyzed, the $\log _{2}$ (fold change) was obtained using the $\mathrm{R}$ package Deseq2, and its correction was performed using the R package Apeglm (Zhu et al., 2019). For the DEGs discovered within the refined hcmQTL, gene ontology (GO) analysis was performed using the GENEDENOVO cloud platform (https://www.omicshare.com/tools/).

Subsequently, to identify the expression of the reported DEGs in the wheat tissues, the transcriptomics data of cultivar Azhurnaya 209-sample RNA sequencing project, which examined the developmental timeline of commercial cultivars using a comprehensive array of samples from 24 tissue types (Ramírez-González et al., 2018), were used in this study. The 
stages and their corresponding tissues are as follows: seedling stage, which includes radicle, coleoptile, stem axis, first leaf sheath, first leaf blade, first leaf blade, root, and shoot apical meristem; three leaf stage, which includes third leaf blade and third leaf sheath; tillering stage, which includes first leaf sheath, first leaf blade, shoot axis, and shoot apical meristem; full boot, which includes flag leaf sheath and flag leaf blade; ear emergence, which includes flag leaf sheath and flag leaf blade; anthesis, which includes flag leaf blade night $(-0.25$ h) 06:45 and fifth leaf blade night $(-0.25$ h) $21: 45$; milk grain stage, which includes flag leaf sheath, flag leaf blade, and fifth leaf blade (senescence); dough, which includes flag leaf blade (senescence); and ripening, which includes flag leaf blade (senescence). Transcripts per million (TPM) values were used to assess the candidate genes' level of expression within the hcmQTL displayed on the heat map using $\log _{2}(\mathrm{TPM}+1)$.

\section{3 | RESULTS}

\section{1 | QTL compilation and projection on the consensus map}

A comprehensive search for QTL conferring resistance to leaf rust resulted in 50 articles published from 1999 to 2020 (Supplemental Table S1). A total of 393 QTL widely distributed across the genome were collected (Supplemental Table S2).

Of the 393 QTL found, only 320 QTL had flanking markers and were thus used for MQTL analysis, leaving 73 QTL with no flanking markers on the consensus map (Supplemental Table S2). The QTL were then projected onto the consensus map constructed by Venske et al. (2019). The highest number of QTL (264) was projected on the B genome, while the D genome harbored the lowest number of QTL (59) (Figure 1). For the A genome, chromosome 2A had the highest number of projected QTL, while chromosomes 4A and 7A equally had the lowest (8). Chromosome 1B had the highest number of projected QTL (41) for the B genome, while chromosomes 4B and 5B both had the lowest (14). The overall number of QTL projected on the $\mathrm{D}$ genome was relatively low compared with other genomes, with the highest number of QTL (22) projected on chromosome 2D, while 6D did not harbor any projected QTL. When the trait was considered, a large proportion of the projected QTL were for disease severity (43\%), followed by AUDPC (24\%) (Figure 1). The rest of the trait categories tagged 'others,' comprised 11 traits (SPS, SPL, IE, LS, EA-, EA+, EST-, EST+, NEC, MDS, and HR). The PVE varied from 0.01 to 0.97 , with $69 \%$ of the QTL reporting a PVE value $<0.20$. Confidence intervals ranged from 1.14 to $173.11 \mathrm{cM}$, with an average of $63.98 \mathrm{cM}$. Most of the QTL reported a CI $<20 \mathrm{cM}$ (81\%), with 57\% of the QTL showing a CI $<10 \mathrm{cM}$. Only $2 \%$ of the QTL showed a CI $>50 \mathrm{cM}$.

\section{2 | Unravelling consensus regions via MQTL analysis}

For the MQTL analysis, the Veyrieras approach (Veyrieras et al., 2007) was used to analyze all the linkage groups except for chromosomes 1A, 4A, 5A, 7A, 3D, 4D, and 5D because they had $<10$ QTL; thus, the approach of Goffinet and Gerber (2000) was used for their analysis. Overall, 75 MQTL were discovered and distributed across all the chromosomes (Figure 1; Table 1). For the reported MQTL, the CI ranged from 0.03 to $25.23 \mathrm{cM}$ with an average of $5.36 \mathrm{cM}$. For the A genome, 24 MQTL were found, with the highest number of MQTL (4) on chromosomes 1A, 5A, and 7A, while chromosomes 2A, 3A, 4A, and 6A harbored three MQTL. For the $\mathrm{B}$ genome, a total of $33 \mathrm{MQTL}$ were found, representing the genome with the highest number of MQTL. Chromosome 2B reported the highest number of MQTL (8), followed by six MQTL on chromosomes $1 \mathrm{~B}$ and $6 \mathrm{~B}$, and chromosomes $3 \mathrm{~B}$ and 4B had the lowest number, with three MQTL. For the D genome, a total of 18 MQTL were found, with chromosomes 1D, 2D, and 7D harboring the most MQTL (4), while chromosomes 3D, 4D, and 5D harbored the fewest MQTL (2). The physical position of all the MQTL was computed. The mean physical confidence interval of the MQTL was $27.47 \mathrm{Mb}$, which ranged from 0.55 (MQTL1D.1) to 765.3 $\mathrm{Mb}$ (MQTL2B.7). The MQTL7B.4 incorporated the highest number of original QTL. From the MQTL discovered, the physical interval of six MQTL was shown to overlap, namely, MQTL1B.2 (636-648 Mb) and MQTL1B.3 (646-662 Mb), MQTL7B.3 (734-744 Mb) and MQTL7B.4 (724-750 Mb), and MQTL5B.4 (634-712 Mb) and MQTL5B.3 (685-704 $\mathrm{Mb})$. Interestingly, none of the MQTL whose physical intervals overlapped did it in the genetic map.

\section{3 | Association study validation and colocalization with leaf rust genes}

The loci resistant to leaf rust across different genetic backgrounds and environments identified in recent association studies (Supplemental Table S3) were used to validate the MQTL discovered in this study. A total of 51 marker-trait associations identified were colocalized with 29 MQTL; thus, some MQTL integrated more than one marker-trait association (Supplemental Table S4; Figure 2). Furthermore, eight leaf rust genes colocalized with some MQTL found in this study (Supplemental Table S5; Figure 2), such as MQTL1D.2 colocalizing with $L r 60$ and $L r 42$ and MQTL7B.3 colocalizing with the Lr68 and Lr14a genes. Additionally, MQTL1B.4 and MQTL2B.5 colocalized with two leaf rust genes, $L r 46$ and $L r 13$, respectively, conferring adult plant resistance. 


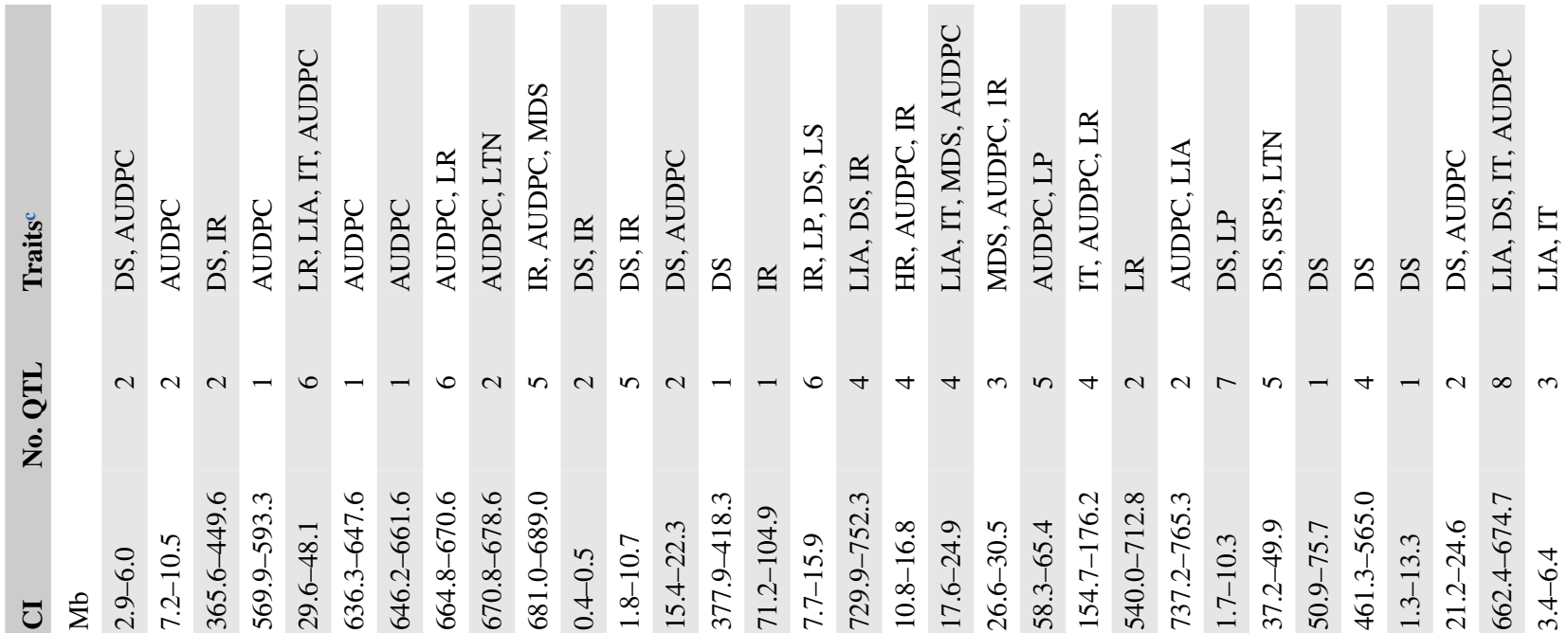

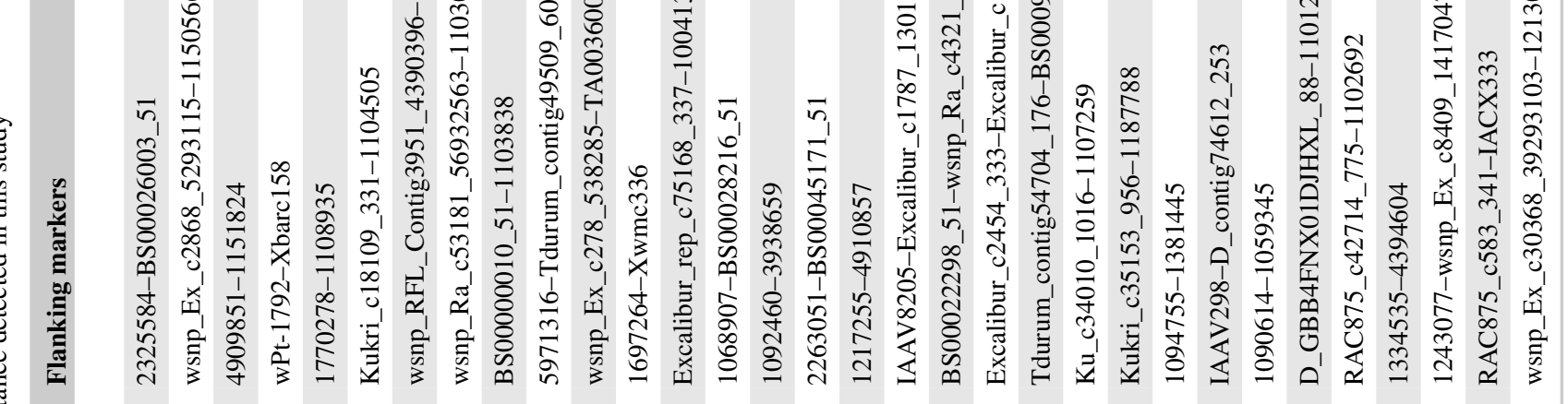

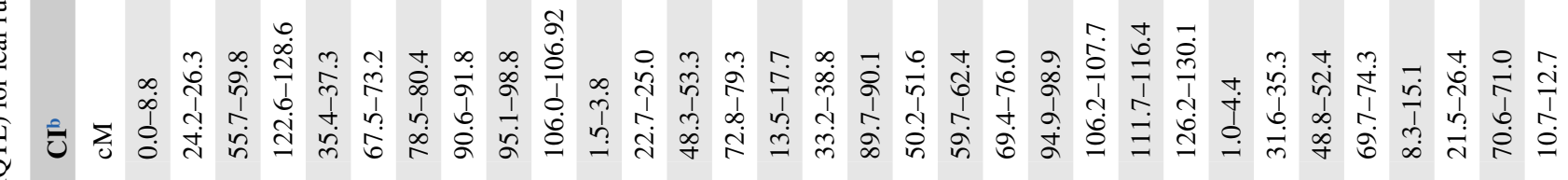

$\stackrel{3}{2}$

$\overline{8}$

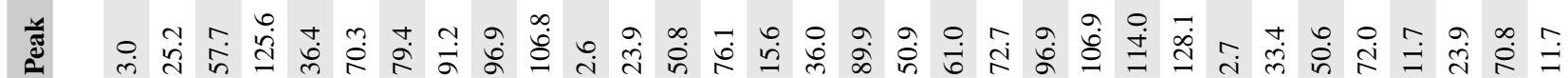

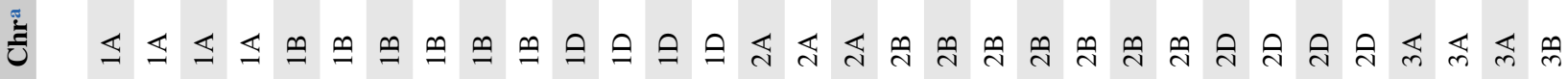
$\stackrel{\Xi}{E}$

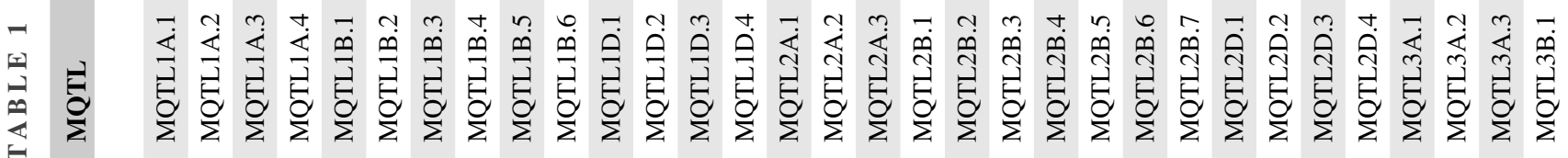




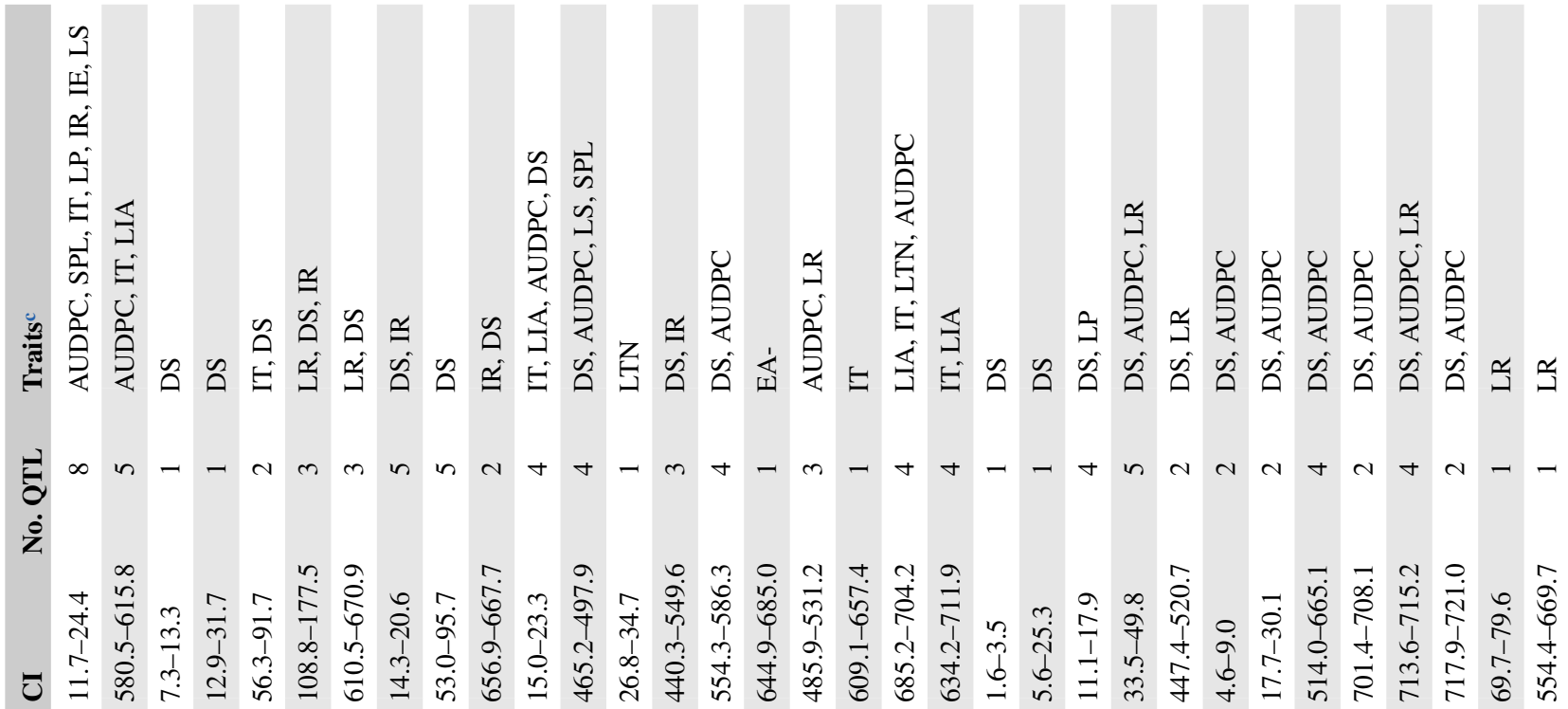

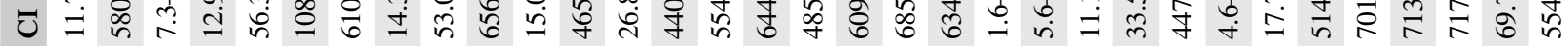

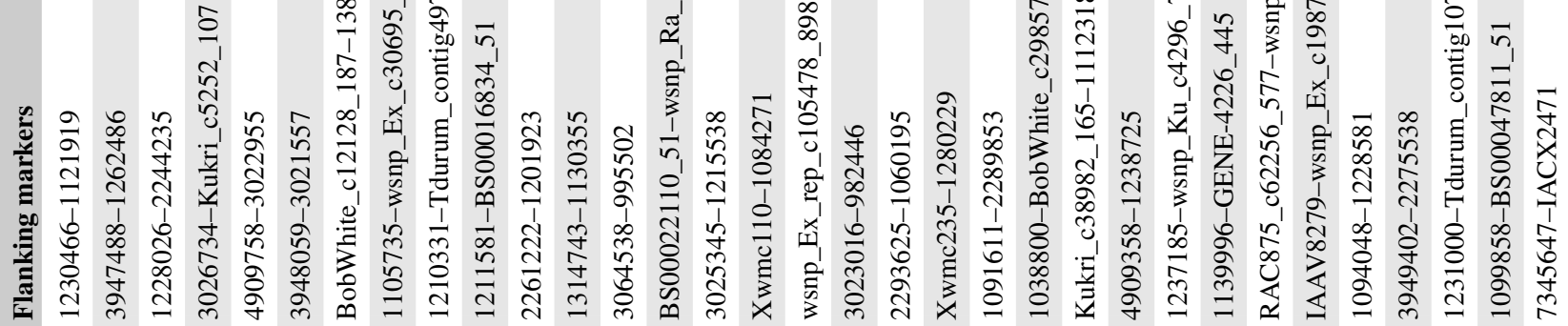

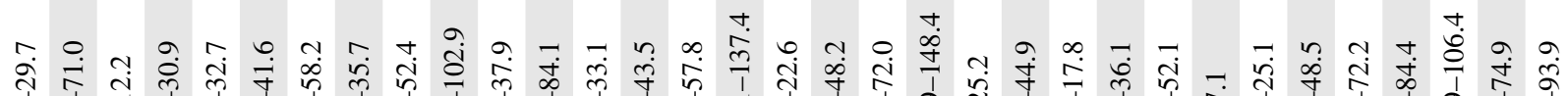

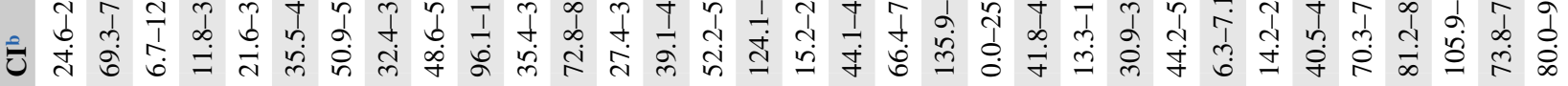

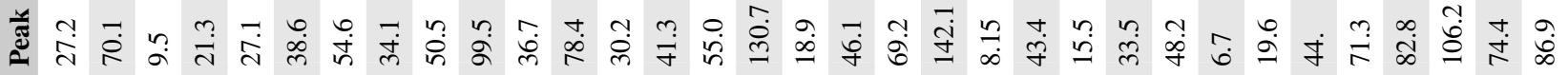

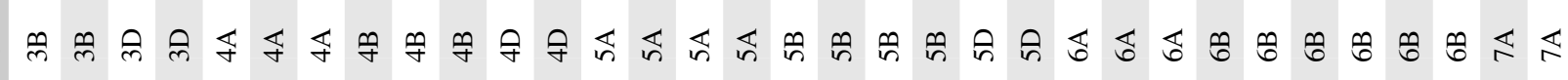

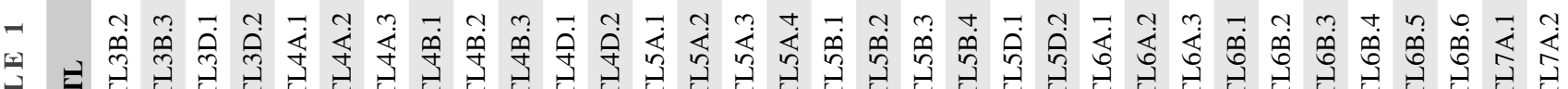

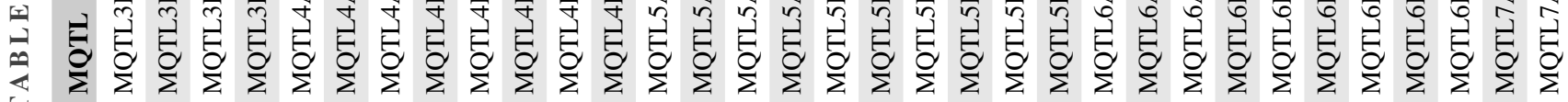




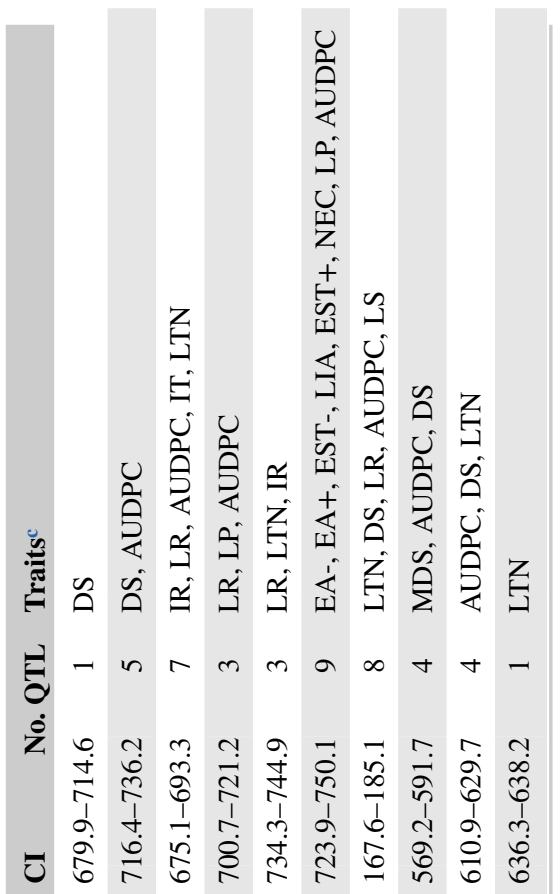

青占

है

芌

政

के

के

敬

离

类苞

की

总窟

䒠衣芯

.

它

洁.

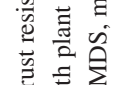

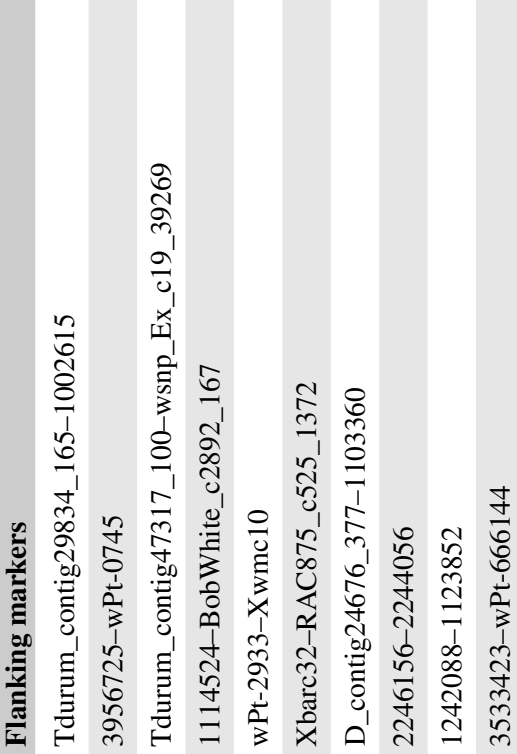

焉

궘

㱐

产

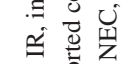

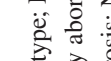

흘 긍

峞

的空

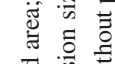

这

崖

氙

过苞总

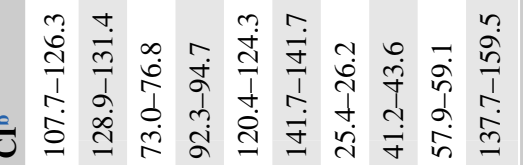

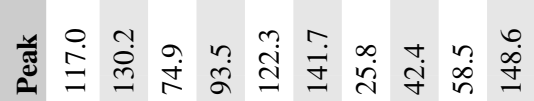

ป⿺尢丶

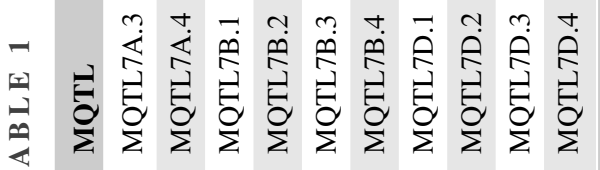

客 

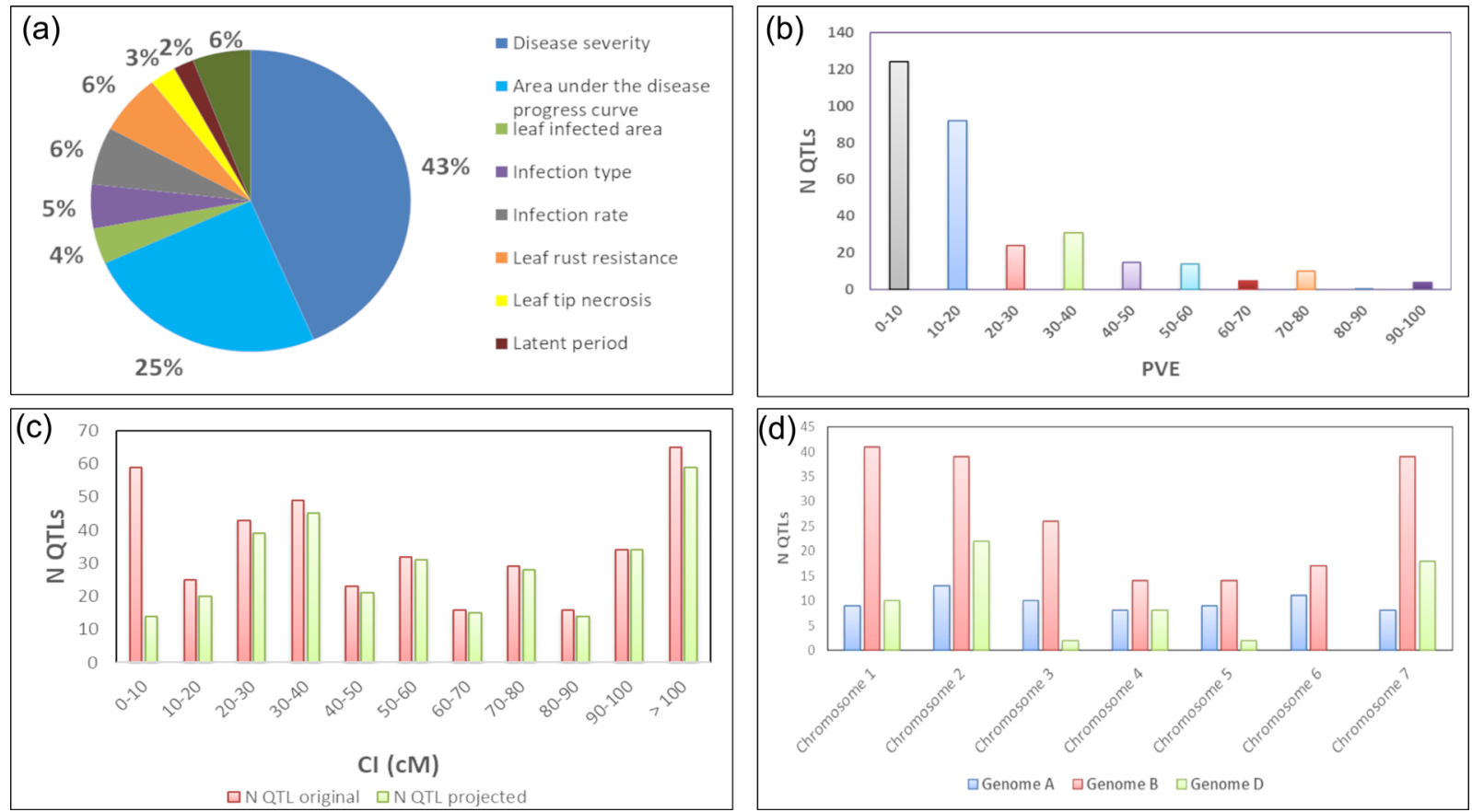

F I G U R E 1 Summary information of quantitative trait loci (QTL) projected for meta-QTL (MQTL) analysis. Frequency distribution of the number of QTL by (a) type of resistance trait conferred by the QTL; (b) phenotypic variation explained (PVE/ $R^{2}$ ); (c) confidence interval; and (d) number of QTL per chromosome

\section{4 | Candidate gene mining of established hemQTL}

To further improve the quality of the MQTL discovered, they were further refined to regions termed homQTL. The hcmQTL consist of 15 consensus regions (Table 2; Supplemental Table S6), having an average CI and physical interval of $2.9 \mathrm{cM}$ and $12.04 \mathrm{Mb}$, respectively. Overall, each hcmQTL cluster contained at least five QTL. The B genome had the highest number of these homQTL (7). Within the B genome, chromosome 1B contained the highest number of hcmQTL (3). In addition, hcmQTL4B.1 had the smallest physical interval $(6.25 \mathrm{Mb})$, while homQTL7A.4 had the largest interval, covering $19.78 \mathrm{Mb}$. Afterward, candidate gene mining within hcmQTL revealed 2,240 genes, with homQTL7A.4 possessing the highest number of candidate genes and hcmQTL2B.4 possessing the lowest number (18) of candidate genes.

\section{5 | Discovering DEGs within hcmQTL}

Owing to the lack of transcriptomic data repositories for leaf rust in wheat, we decided to use transcriptomic expression data for three fungal diseases in wheat-stripe rust, powdery mildew, and Septoria tritici blotch - to explore the DEGs within these hcmQTL. The ERP013983 dataset revealed 541 DEGs with 221 downregulated genes, 255 upregulated genes, and 65 genes that were downregulated under several conditions and upregulated under others (Supplemental Table S7; Figure 3). From this dataset, hemQTL7A.4 had the highest number of DEGs (59), while homQTL2B.4 had the lowest (12). The SRP041017 dataset revealed 289 DEGs, where 131 genes were downregulated, 154 genes were upregulated, and four genes were downregulated at one time point and upregulated in others (Supplemental Table S8; Figure 3). From this dataset, hcmQTL2A.2 had the highest number of DEGs (39), while homQTL2B.4 and homQTL4B.1 had the fewest DEGs (4). From the third dataset, ERP009837, a total of 327 DEGs were discovered, with 125 genes downregulated, 198 genes upregulated, and four genes downregulated at one time point and upregulated in others (Supplemental Table S9; Figure 3). From this dataset, hcmQTL2A.2 had the highest number of DEGs (34), while hcmQTL2B.4 had the lowest number of DEGs (3). A total of 92 genes were found to be differentially expressed across the three expression datasets used. The 92 DEGs within the hcmQTL interval were analyzed for GO enrichment (Table 3). The most significantly enriched GO terms associated with biological processes were for metabolic (44 genes) and cellular processes (31 genes) (Supplemental Table S10; Figure 4). The most significantly enriched GO terms associated with molecular function were for catalytic activities (41 genes) and binding (39 genes). In terms of cellular components, the genes were enriched mainly in the cell membrane and its components. 


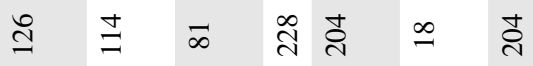

ト

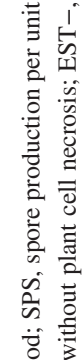

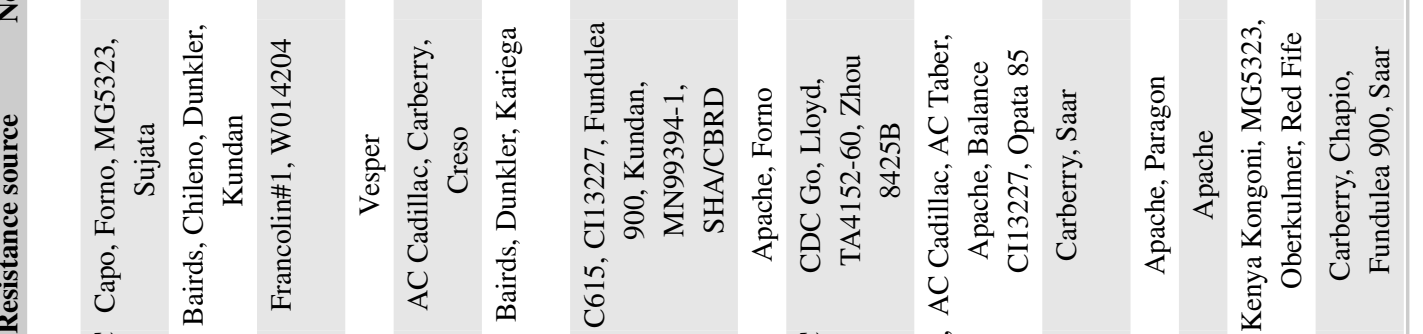

:

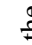

总

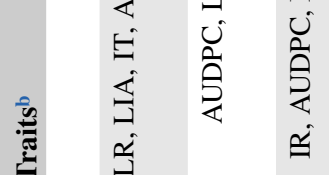

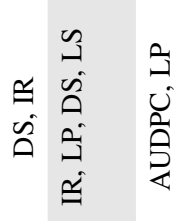

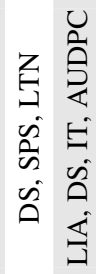

至

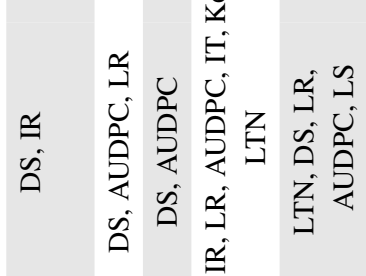

离

盗

离

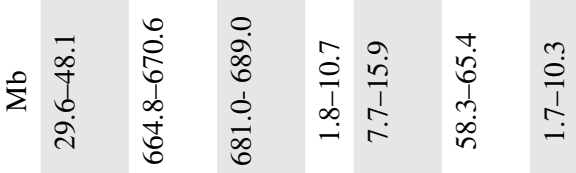

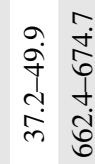

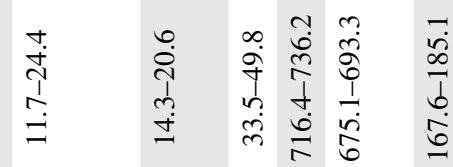

ठ

党

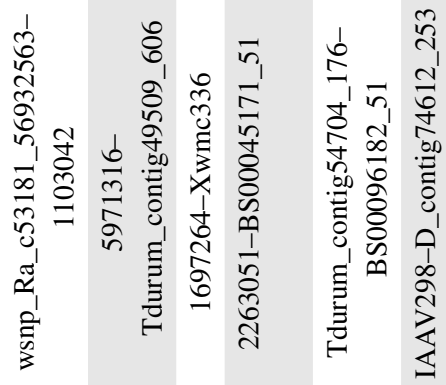

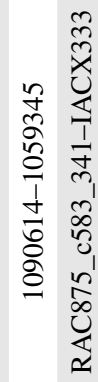

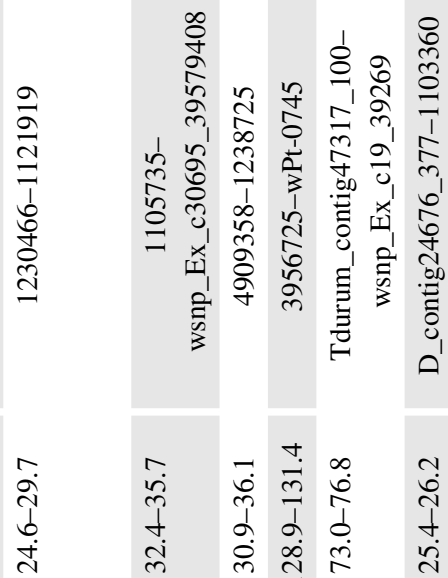

这.

항

ब $\overrightarrow{0}$

然

言畜

$\exists+$

可

$\frac{0}{\vec{b}}$

离

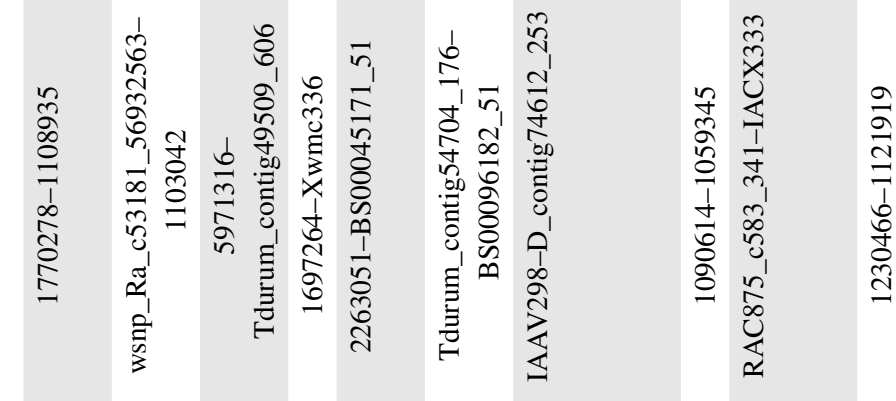

营票

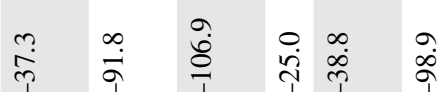

İ:

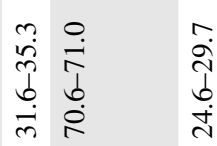

in $n$ in $\infty$

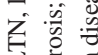

密 范

ठ․

营

일

宛

ڤั

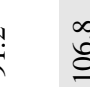

$\stackrel{0}{0} \quad \sigma$

$\cos$

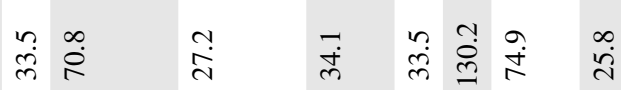

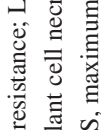

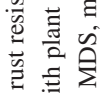

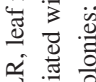

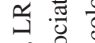

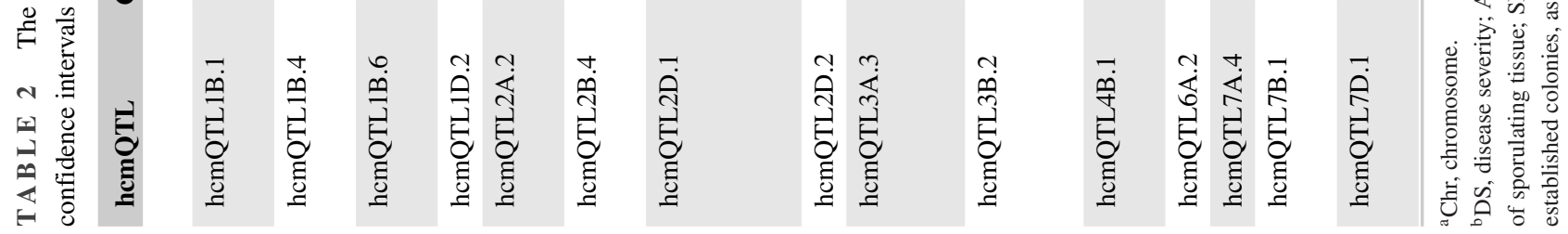

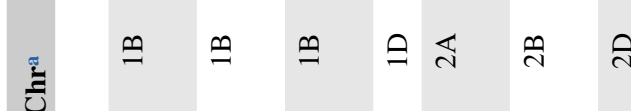

ลิ

$m$

守

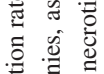




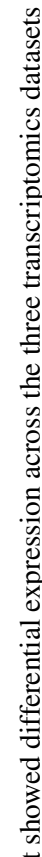

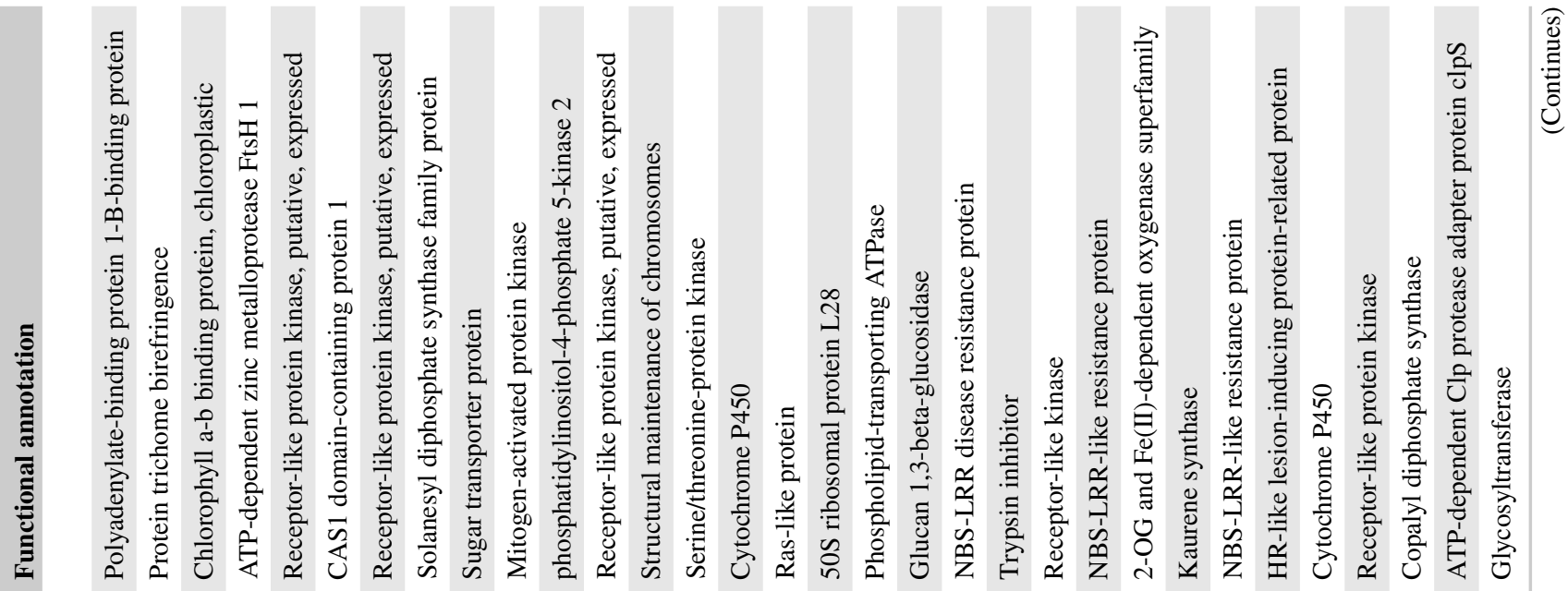

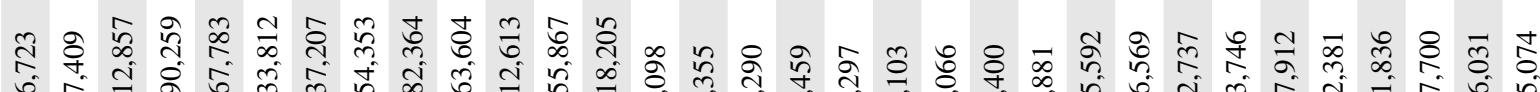

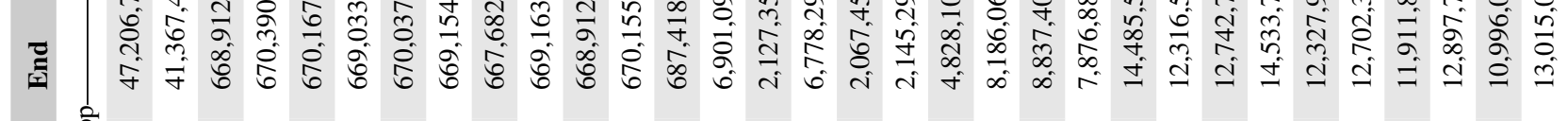
ô

\&

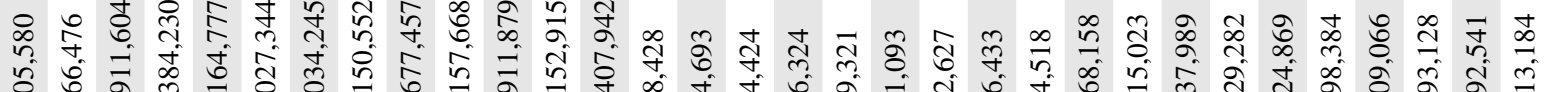

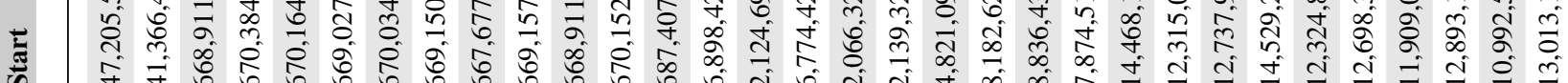
के

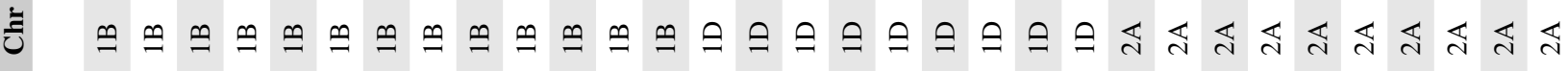

产

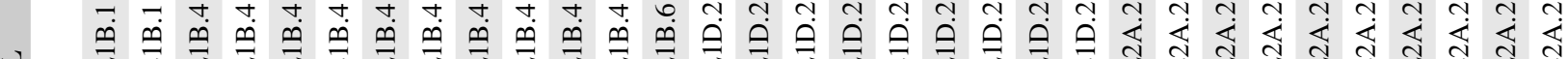

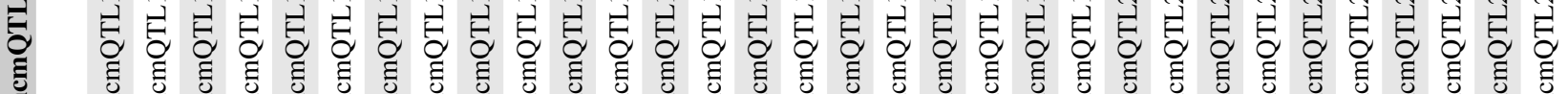

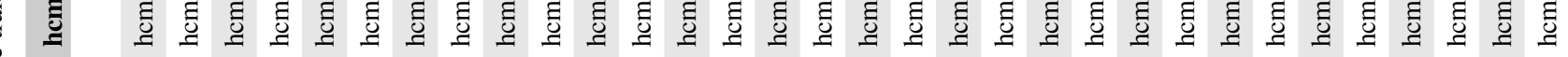

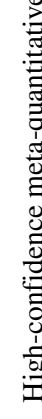

离

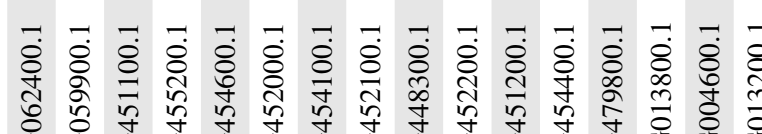

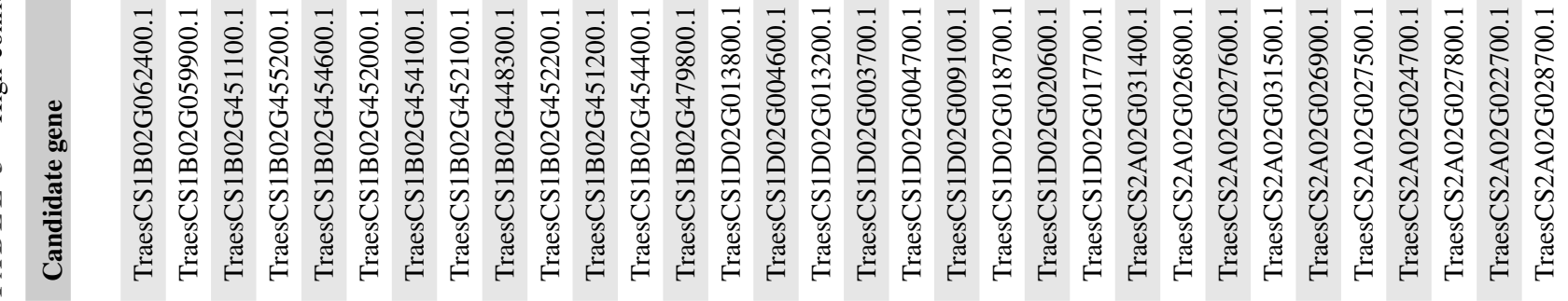




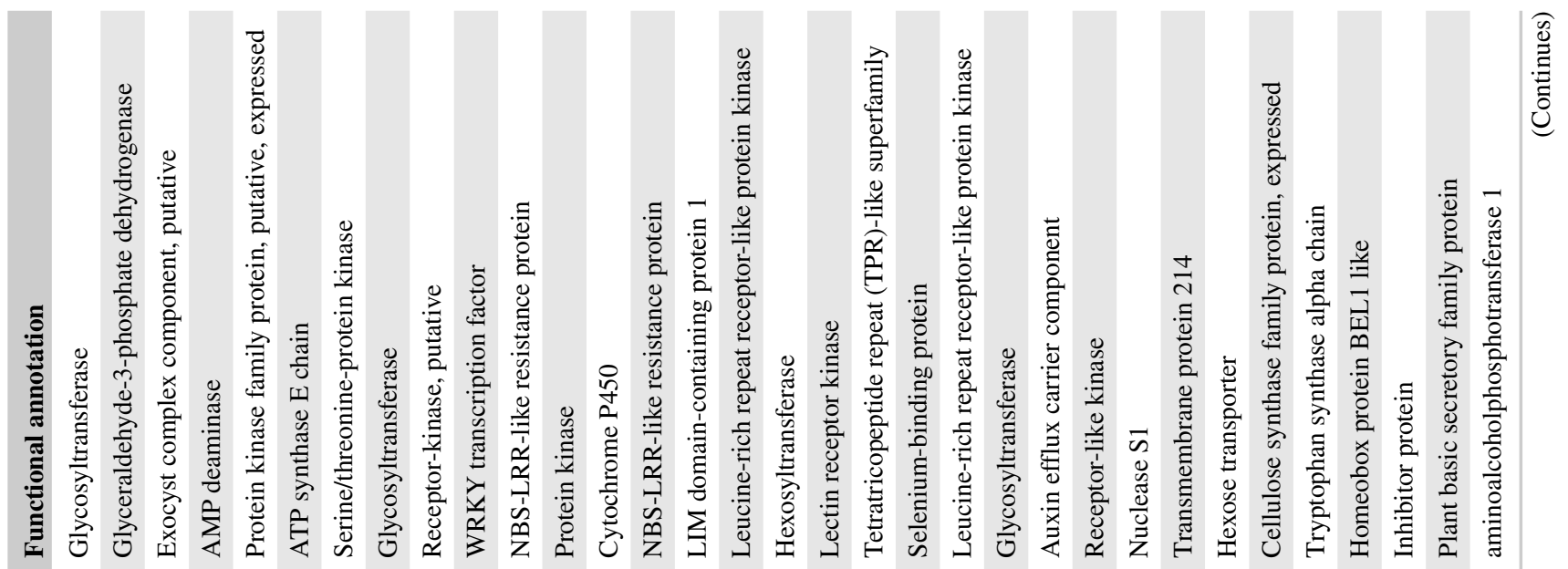

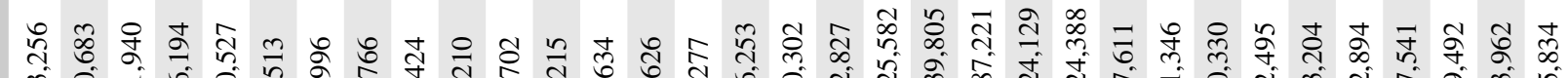

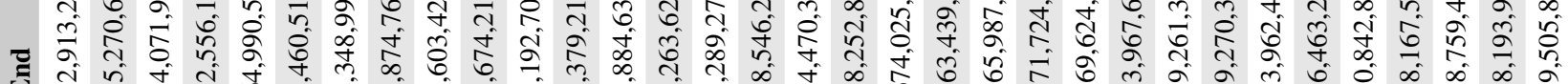

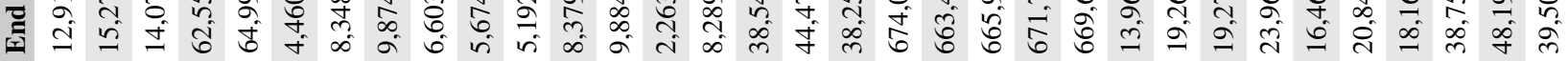

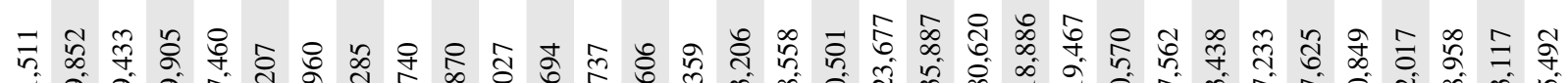

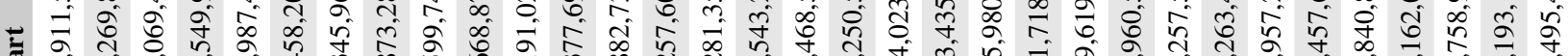

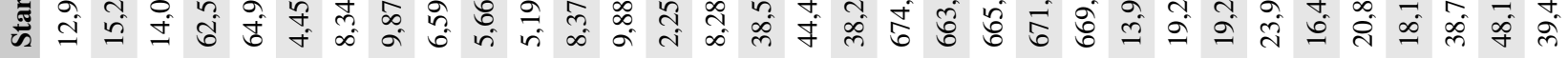

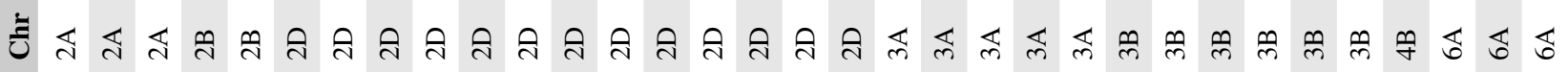

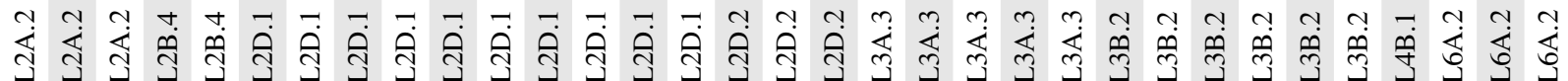

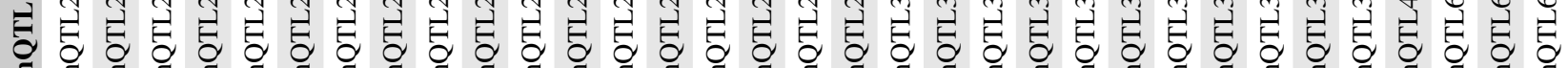
㢦

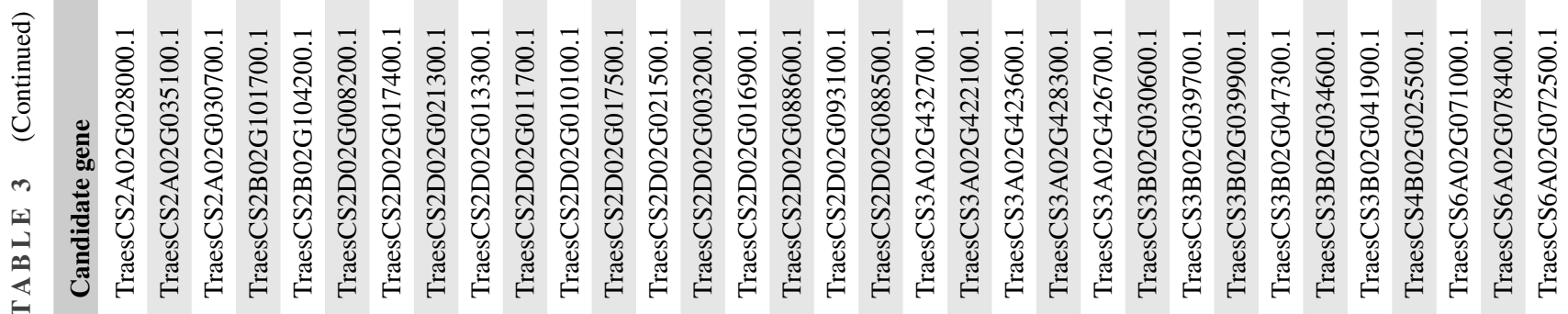




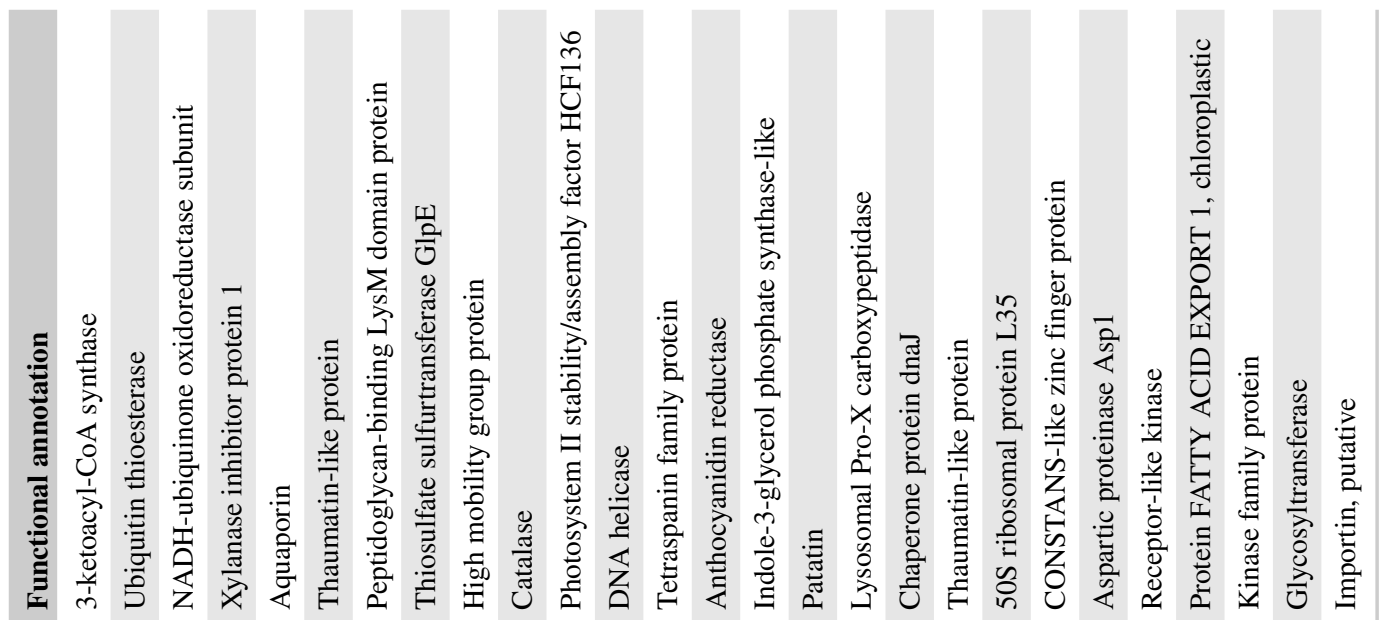

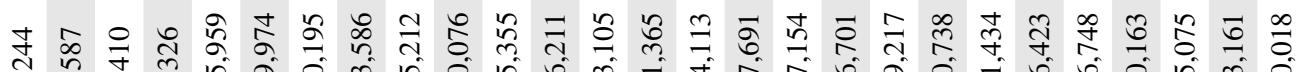

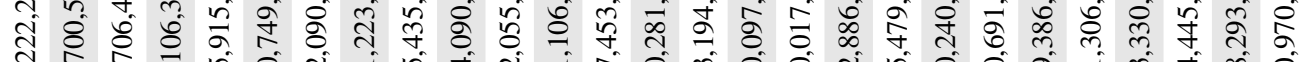

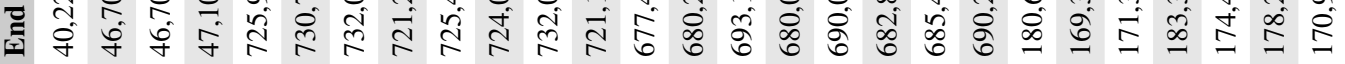

긓

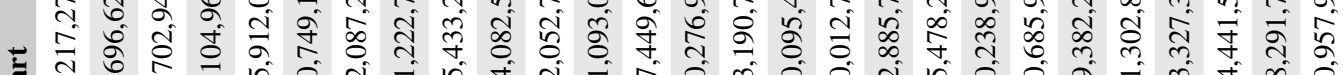

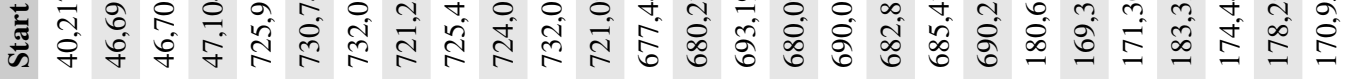

ป

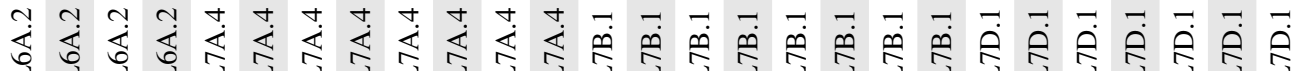

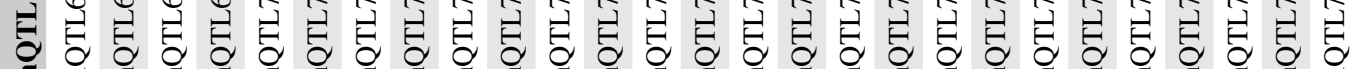
掝 
F I G URE 2 Distribution of the meta-quantitative trait loci (MQTL), marker-trait associations (MTAs), and colocalized leaf rust genes with reference to the Chinese Spring genome. The chromosome coloration correlates to the number of initial QTL, the lighter color connotes less QTL. The centromere of each chromosome is represented by the constriction

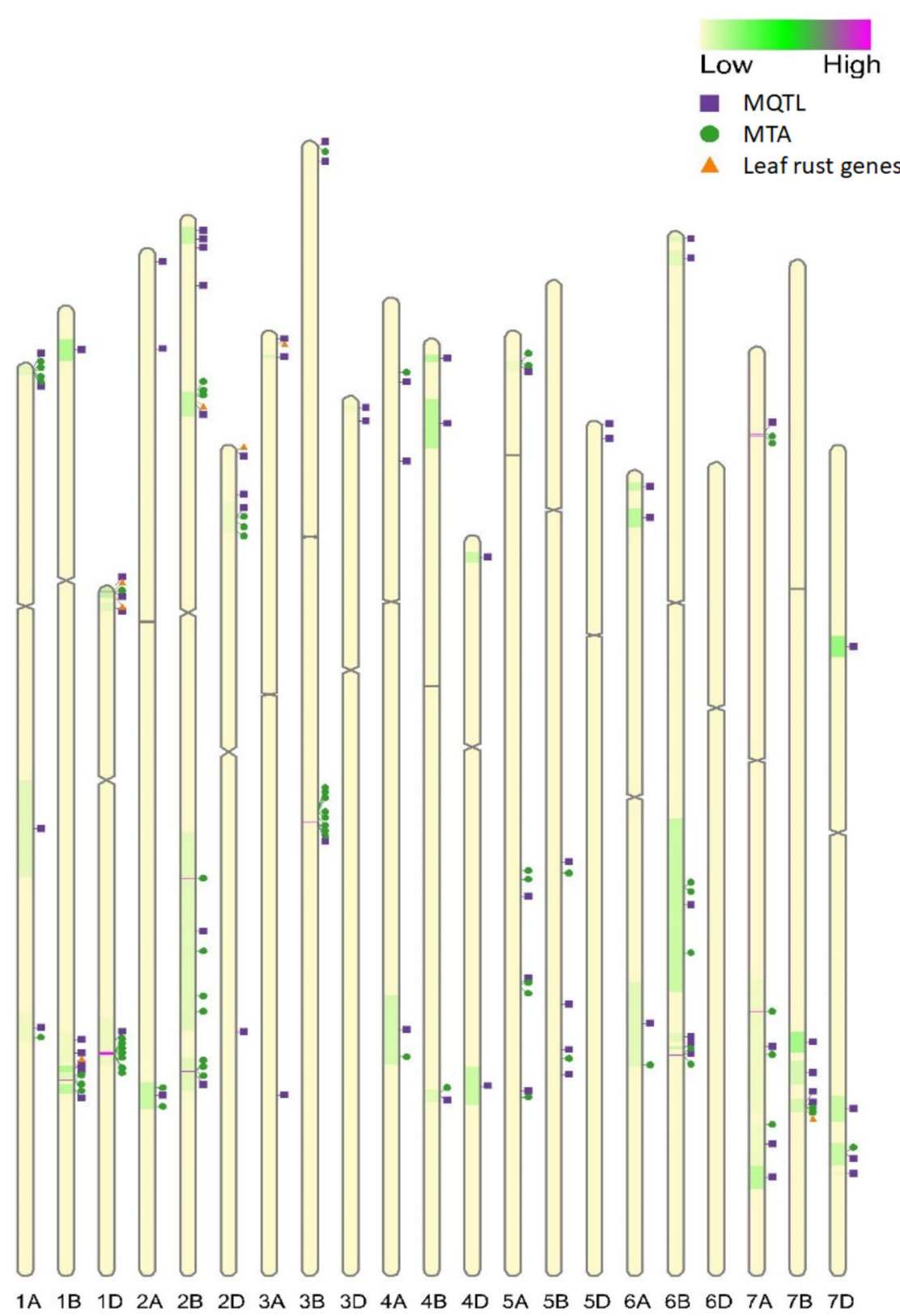

\section{6 | Tissue-specific expression profile of DEGs within hcmQTL}

To analyze the differential expression within the hcmQTL at different tissues and development stages, three transcriptomics datasets were used: SRP041017, ERP013983, and ERP009837. Row clustering was applied, and, as a result, the 92 DEGs fell into two classes based on their expression patterns (Figure 5). Genes in Class I showed moderate-to-high expression in the flag leaf blade and fifth leaf blade at the anthesis stage when compared with other stages of growth. Moreover, for Class II, more genes were highly expressed in the first leaf sheath at the tillering stage. The DEGs in Class II accounted for more than half of the overall DEGs, and they showed contrasting expression patterns to those shown by genes in Class I. For Class I, at the seedling stage, the genes TraesCS1D02G003700 (hcmQTL1D.2) and TraesCS7B02G421100 (hcmQTL7B.1) showed moderate expression in the stem axis, while at the adult stage, TraesCS6A02G072500 (hcmQTL6A.2) was highly expressed in the fifth leaf blade at the anthesis stage, and TraesCS1D02G017700 (hcmQTL1D.2) showed high expression in the flag leaf at the dough stage. Furthermore, at the seedling stage, more Class II genes were moderately expressed in the radicle and roots, with only TraesCS7D02G211000 (hcmQTL7D.1) showing expression in the shoot apical meristem. At the adult stage, the gene TraesCS7D02G220300 (hcmQTL7D.1) was highly expressed in the fifth leaf blade at the anthesis stage. 


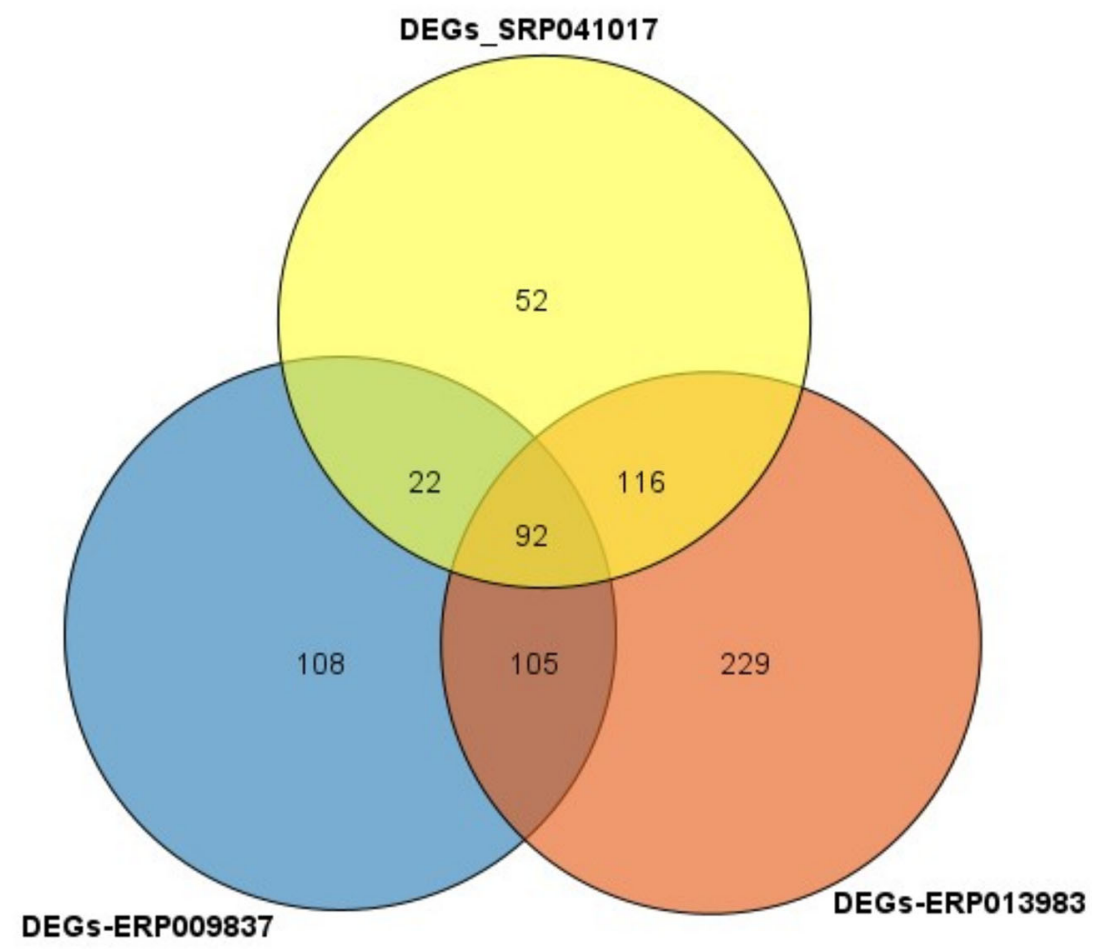

F I G U RE 3 Venn diagram depicting the number of differentially expressed genes (DEGs) from three transcriptomic data sets. The Venn diagram visually illustrates the number of DEGs that were identified in three transcriptomic data sets: ERP013983, SRP041017, and ERP009837

\section{4 | DISCUSSION}

\section{1 | Establishment of MQTL regions}

To gain deeper insight into the control of leaf rust resistance in wheat, an MQTL analysis was performed based on the numerous QTL conferring leaf rust resistance identified in the literature from various independent studies. The first step to identifying consensus regions via MQTL analysis is the projection of the original QTL onto a consensus or reference map.

A feature of the consensus map and QTL database was that the B genome reported the highest marker saturation, and thus, the highest number of QTL was mapped to this genome, which is in agreement with previous studies characterizing genetic diversity and unravelling complex traits for disease resistance in bread wheat (Soriano \& Royo, 2015; Wang et al., 2014). The D genome presented a lower number of QTL, as previously found in other MQTL analyses for disease resistance in wheat (Liu et al., 2020; Soriano \& Royo, 2015; Venske et al., 2019; Zheng et al., 2020). Furthermore, no QTL were found on chromosome $6 \mathrm{D}$, as discovered in previous MQTL analysis studies on leaf rust and Fusarium head blight diseases in wheat (Soriano \& Royo, 2015; Zheng et al., 2020). A possible explanation for the limited QTL located on the $\mathrm{D}$ genome across various disease studies could be the low level of polymorphism associated with the D genome. In this study, a larger number $(81.4 \%)$ of QTL was projected onto the consensus map compared with the fewer number of QTL projected in a previous MQTL analysis for leaf rust (Soriano \& Royo, 2015) (44\%). A possible reason could be due to the different consensus maps used. In this study, we used a high-density consensus map that combined SSRs and markers obtained from high-throughput genotyping platforms, in contrast to the consensus map used in the previous study from Soriano and Royo (2015). Consequently, the number of consensus genomic regions (MQTL) discovered in this study was higher than those reported in Soriano and Royo (2015), at 75 and 48, respectively. For the MQTL discovered in CI interval of the original QTL, ranging from 1.14 to $173.11 \mathrm{cM}$. In addition, in the present study, the physical position of the MQTL was reported because of the release of the wheat genome sequence (The International Wheat Genome Sequencing Consortium et al., 2018), improving the mapping resolution of the genome regions and helping the identification of candidate genes. These analyses enhance the results provided by studies published prior to the release of the genome sequence. In this study, we discovered seven MQTL incorporating at least five original QTL and having a confidence interval of $<10 \mathrm{Mb}$, making them the most promising for candidate gene identification.

\section{2 | Colocalization of MQTL with leaf rust resistance genes and traits}

To strengthen the location of MQTL discovered in this study, a search for colocalization of leaf rust resistance genes and MQTL was performed. More than 61 leaf rust genes have been mapped and documented in wheat (Kim et al., 2020), and four of them have been cloned (Hafeez et al., 2021). A total of six 


\section{Level2 GO Terms}

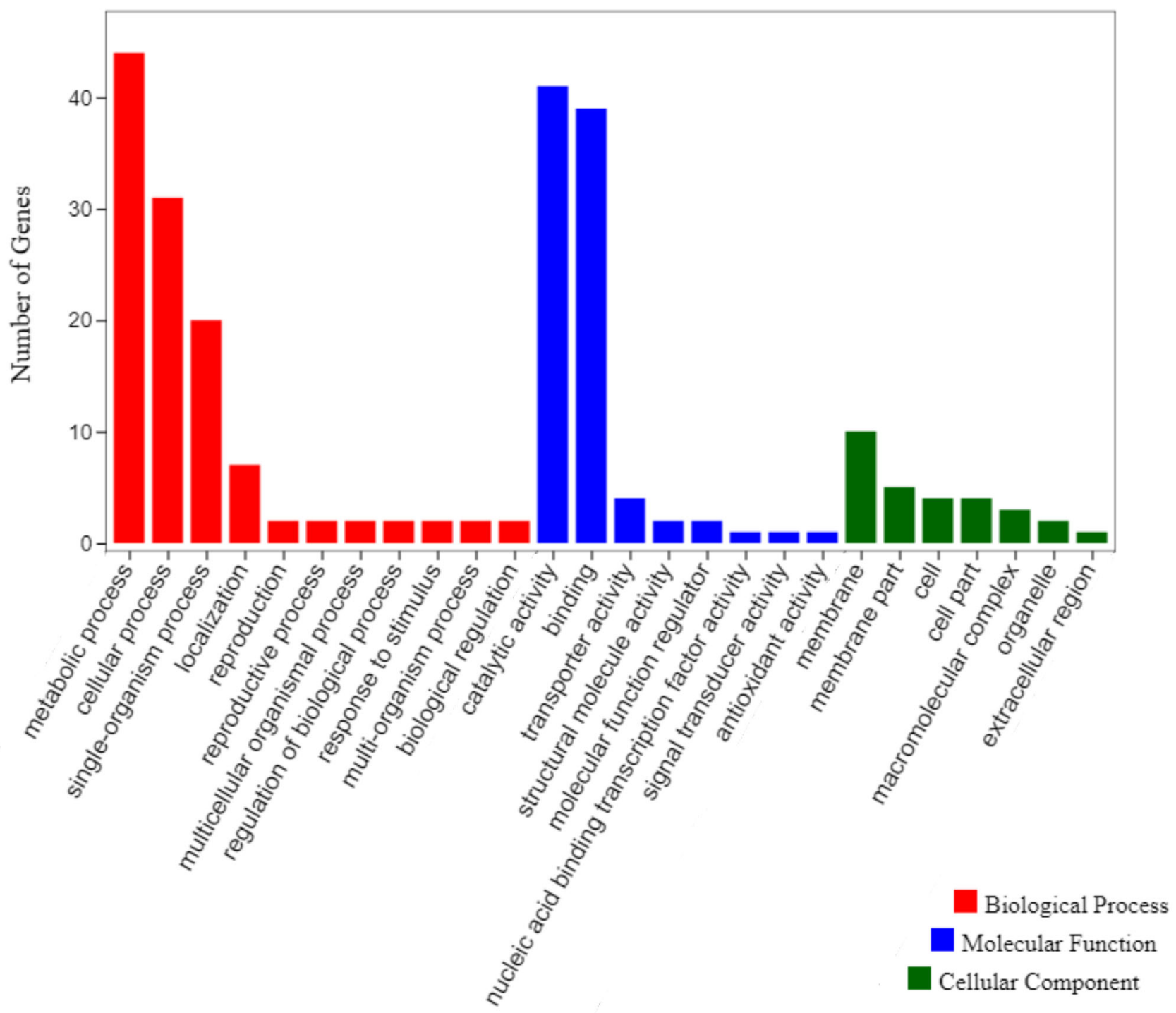

F I G U R E 4 Level 2 gene ontology (GO) terms for differentially expressed genes (DEGs) in the homQTL regions

leaf rust genes ( $\operatorname{Lr} 13, L r 14 a, L r 46, L r 68, L r 63, L r 60, L r 42$, and $L r 41$ ) were found to colocalize with MQTL. Interestingly, the colocalization of $L r 13, L r 14 a$, and $L r 46$ with MQTL2B.5, MQTL7B.3, and MQTL1B.4 on chromosomes 2B, 7B, and $1 \mathrm{~B}$, respectively, in this study was in agreement with the results obtained by Soriano and Royo (2015). As reported by these authors, $\operatorname{Lr} 68$ was found to have a tight association with MQTL33 (colocalized with Lr14a) on chromosome 7B; however, in this study, MQTL7B.3 colocalized with both leaf rust genes ( $L r 14 a$ and $L r 68$ ), thus confirming the usefulness of using highly saturated consensus maps for meta-QTL analysis. The gene Lr14a, known to confer seedling resistance, is thought to have evolved from emmer wheat [Triticum turgidum L. subsp. dicoccon (Schrank) Thell.] 'Yaroslav' (McFadden, 1930) and is associated with the stem rust and powdery mildew resistance genes $\operatorname{Sr} 17$ and Pm5. $\operatorname{Lr} 68$, on the other hand, confers adult plant resistance to the majority of P. triticina isolates with low-to-medium infection types and is linked to small but noticeable leaf tip necrosis (HerreraFoessel et al., 2012). Consequently, the MQTL7B.3 region not only confers seedling and adult plant resistance to leaf rust but also constitutes a region of multiple disease resistance. Additionally, MQTL1D.2 colocalized with two leaf rust resistance genes ( $L r 60$ and $L r 42$ ). Hiebert et al. (2008) found that $L r 60$ is $13.5 \mathrm{cM}$ distal to $L r 21$, which would position $L r 60$ and $L r 42$ approximately $40 \mathrm{cM}$ apart (Huang et al., 2003; Somers et al., 2004). The association between Lr60 and Lr42 has not been confirmed, but in this study, we discovered that both genes were located in the same MQTL, with a CI of $8.8 \mathrm{Mb}$. This supports possible linkage between the two genes; however, a genetic linkage test needs to be carried out to corroborate this claim. Furthermore, Lr60 is known to confer seedling 
resistance, while $L r 42$ confers adult plant resistance. Additionally, MQTL1B.4 colocalized with $L r 46$, a gene known to increase the latent period and reduce the frequency of infection and uredinial size in a similar manner to $2 r 34$ (Drijepondt $\&$ Pretorius, 1989; William et al., 2003). There is also a tight linkage between $L r 46$ and a stripe rust gene (Yr29), which is similar to the linkage between Lr34 and $\mathrm{Yr} 18$ (McIntosh, 1992; Singh, 1992). Consequently, the MQTL1D.2 region confers resistance to both leaf and stripe rust in wheat, thus making this region a hotspot for selecting multiple disease resistance in wheat.

Most of the MQTL discovered in this study clustered QTL conferring two or more resistance traits. In another study, Ren et al. (2012) also discovered that maximum disease severity had a significant association with the AUDPC across diverse environments, and this finding was in agreement with previous studies (Lan et al., 2009; Liang et al., 2006; Wang et al., 2005). Consequently, this result indicates the possibility of replacing AUDPC with MDS. A possible explanation for this could be that when two or more traits are mapped to the same region, they are most likely under the same genetic control, as suggested by Lu et al. (2017). Furthermore, effects arising from tight linkage and pleiotropism could also be a possible explanation.

\section{3 | Candidate genes within hcmQTL and their role in leaf rust resistance}

The search for candidate genes was extended to hcmQTL within $20 \mathrm{Mb}$, thus yielding $15 \mathrm{hcmQTL}$. The hcmQTL also have a small CI compared with MQTL, thus making them more reliable and useful for QTL selection in breeding programs. Gene annotation of the hcmQTL identified a total of 2,240 genes, which were narrowed down to 92 DEGs after in silico transcriptomic analysis. Two main types of disease resistance are used in breeding programs: seedling resistance and adult plant resistance. Thus, the analysis of the expression of the candidate genes across different tissues and developmental stages can inform us of their potential role in seedling or adult plant resistance. Five out of the 92 genes expressed across the three transcriptomic data sets-TraesCS7D02G212800, TraesCS6AOG073300, TraesCS2B02G104200, TraesCS1D02G003700, and TraesCS2D02G021300-showed moderate expression in the first leaf sheath at the seedling stage. TraesCS7D02G212800 and TraesCS2B02G104200 encode a receptor-like kinase (RLK) and protein kinase family protein, respectively, and both proteins play a crucial role in contributing to disease resistance in wheat. Plant protein kinases, as well as RLKs, govern the detection and activation of diverse developmental and physiological signals, particularly those involved in defense and symbiosis (Rentel et al.,
2004; Abu-Qamar et al. et al., 2008; Fu et al. et al., 2009; Garcia et al. et al., 2012). Prior studies found that various RLK genes coding wheat leaf rust kinases were conserved in wheat, with the most studied member of the wheat leaf rust kinase family being LRK10, which is genetically linked to the Lr10 locus (Feuillet et al., 1997, 1998, 2001). Gu et al. (2020), in a recent study, uncovered an RLK gene that plays an important role in resistance to $P$. triticina infection and has a positive regulatory effect on the hypersensitive reaction cell death process induced by P. triticina. TraesCS6A02G073300, encoding a 3-ketoacyl-CoA synthase, has been reported to harbor quantitative trait nucleotides in close proximity to leaf rust resistance genes in wheat (Fatima et al., 2020). The 50S ribosomal protein L28 encoded by TraesCS1D02G003700 belongs to the ribosomal protein family, and members of this family have been shown to confer tolerance against fungal pathogens in plants (Yang et al., 2013). Furthermore, TraesCS7D02G217700, encoding a glycosyltransferase, was highly and moderately expressed in the first leaf blade and leaf sheath, respectively, at the seedling stage. According to Bolton et al. (2008), two pathogen-responsive genes encoding glycosyltransferases were shown to be upregulated under leaf rust infection. At the adult plant stage, TraesCS1D02G004600, encoding a cytochrome P450, was expressed in the flag leaf blade at both the dough and ripening stages. Different studies have reported the role played by cytochrome P450 in the host response to disease, which included the response to Fusarium head blight disease in wheat (Walter et al., 2008). The pathogen-responsive gene encoding cytochrome P450 has been shown to be differentially expressed under leaf rust infection in wheat (Bolton et al., 2008). Additionally, Bolton et al. (2008) reported that gene models coding for the same protein as some of the hcmQTL discovered in this study were upregulated under leaf infection. All gene models coding for serine-threonine protein kinases and cytochrome $\mathrm{P} 450$ were upregulated in all treatments.

\section{4 | Breeding implications for leaf rust resistance}

The primary use of MQTL for breeding purposes is the development of improved cultivars with enhanced yield that are resistant to diseases via MAS. Those MQTL with the smallest CIs have been harnessed effectively for MAS because they incorporate multiple QTL, as reported for disease resistance in maize (Zea mays L.) (Xiang et al., 2012; Wang et al., 2016), grain yield-associated traits in rice (Oryza sativa L.) (Wu et al., 2016; Carrijo et al., 2017), seed quality in soybean [Glycine $\max$ (L.) Merr.] (Qi et al., 2017), and anthesis time in wheat (Griffiths et al., 2009). To this end, the MQTL were refined to $15 \mathrm{hcmQTL}$, each of them 


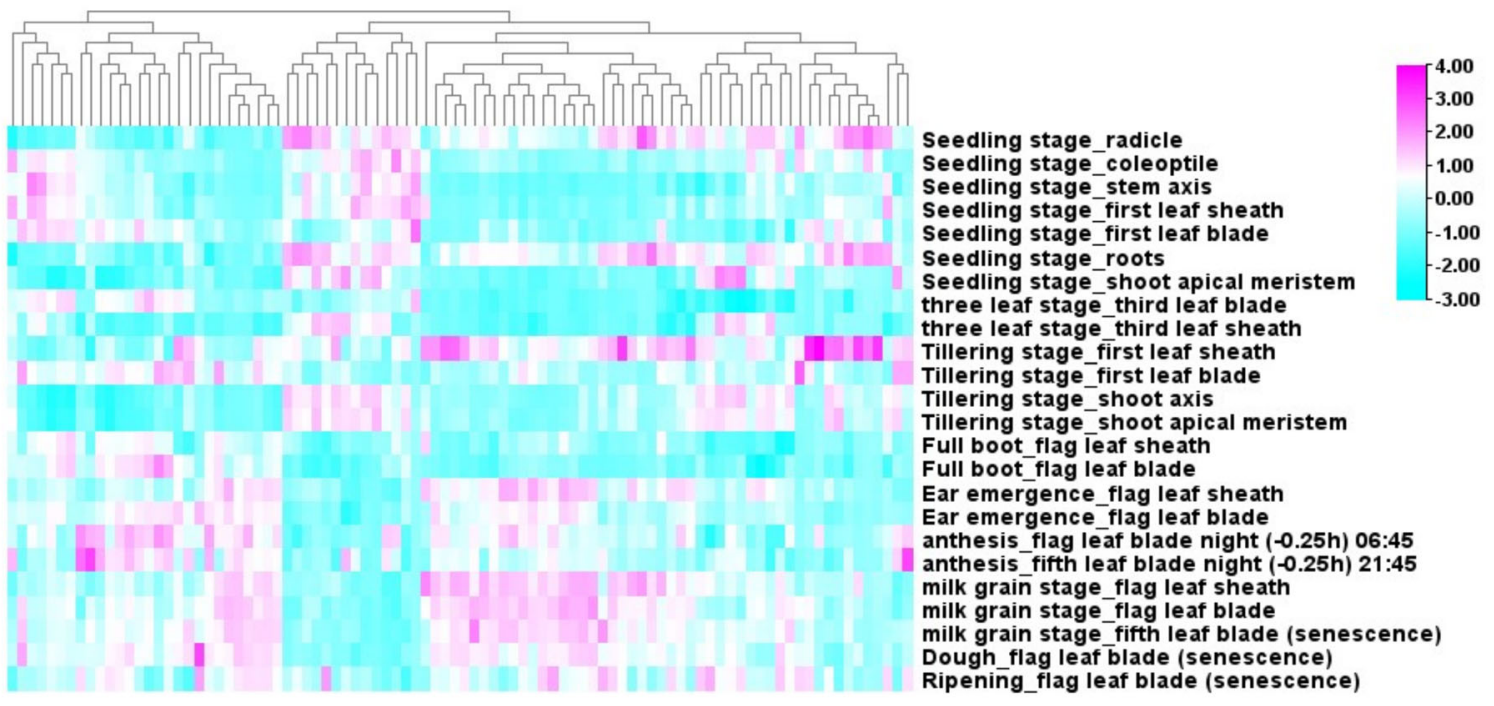

F I G U R E 5 Expression pattern of 90 candidate genes in 24 tissues. All transcriptome data was downloaded from expVIP (http://www.wheat-expression.com). The changes in color from sky blue to pink signifies alteration in level of expression from low to high

incorporating at least five original QTL and having a physical interval $<20 \mathrm{Mb}$ and a genetic interval $<10 \mathrm{cM}$. In addition, MQTL analysis can be used to identify regions that confer resistance to more than one disease, and the marker information can be used for MAS (Ali et al., 2013). In this study, the hcmQTL1B.4 region was identified to confer resistance to leaf and stripe rusts, thus making it a potential region to exploit for multiple disease resistance in wheat. Furthermore, breeding for durable resistance is desired in major breeding programs. Durable resistance remains effective against a pathogen for a significant number of years (Johnson, 1981, 1984). The combination of seedling resistance and adult plant resistance has been proven to confer prolonged resistance over several years (Kolmer \& Oelke, 2006). In addition, various studies have ascribed durable leaf rust resistance to adult plant resistance rather than to seedling resistance (Figlan et al., 2020). Therefore, hcmQTL1D.2, discovered in this study, can be harnessed to confer durable resistance in wheat, as it incorporates genes conferring both seedling and adult plant resistance. Another useful approach that could be harnessed in breeding for leaf rust resistance in wheat is gene pyramiding. Gene pyramiding involves incorporating multiple desired genes into a single cultivar. Gene pyramiding is broadly acknowledged by breeders, plant pathologists, and farmers to improve disease resistance in wheat (Chen \& Kang, 2017). A major requirement for gene pyramiding is to identify various QTL or genes conferring resistance and then incorporate them into a high-yielding cultivar (Singh, 1992). In several instances, this technique has been used in crops. For instance, long-term resistance was conferred when diverse genes were pyramided with leaf rust genes (Kolmer, 1996; Bhawar et al., 2011; Aboukhaddour et al., 2020; Babu et al., 2020). Additionally, in barley (Hordeum vulgare L.), MAS combined with gene pyramiding has been used to introgress resistance loci against stripe rust into numerous lines (Toojinda et al., 1998, 2000; Castro et al., 2003a, 2003b; Richardson et al., 2006). To this end, the hcmQTL discovered in this study can be used and exploited for gene pyramiding via MAS to bolster the resistance of wheat against leaf rust.

\section{5 | Concluding remarks}

One of the most effective methods for analyzing the wealth of QTL information available from various studies is MQTL analysis. In this study, we delineated the genetic architecture of leaf rust in wheat via MQTL analysis and by integrating genomics studies. Compared with initial QTL reports, metaanalysis allowed us to reduce the MQTL CI, thereby facilitating the search for candidate resistance genes in the databases available. The result was the discovery of $15 \mathrm{hcmQTL}$, with each having a potential role in MAS. This result will be useful for developing resistance to leaf rust through the introgression of desirable hcmQTL that could confer a high level of resistance during cultivar development. Last, this study can also help better define the various mechanisms associated with leaf rust resistance in wheat.

\section{DATA AVAILABILITY STATEMENT}

All data supporting the findings of this study are available within the paper and within its supplemental materials published online. 


\section{A C KNOWLEDGMENTS}

This study was funded by project PID2019-109089RB-C31 from the Spanish Ministry of Science and Innovation. JMS thanks the CERCA Programme/Generalitat de Catalunya (http://cerca.cat/) for supporting this research.

\section{AUTHOR CONTRIBUTIONS}

Aduragbemi Amo: Data curation, Formal analysis, Writing original draft, Writing - review \& editing. Jose Miguel Soriano: Conceptualization, Funding acquisition, Methodology, Project administration, Supervision, Writing - review \& editing.

\section{CONFLICT OF INTEREST}

The authors declare no conflict of interest.

\section{O R C I D}

Jose Miguel Soriano (1) https://orcid.org/0000-0003-19656504

\section{R E F E R E N C E S}

Aboukhaddour, R., Fetch, T., McCallum, B., Harding, M., Beres, B., \& Graf, R. (2020). Wheat diseases on the prairies: A Canadian story. Plant Pathology, 69, 418-432. https://doi.org/10.1111/ppa.13147

Abu-Qamar, S., Chai, M. F., Luo, H., Song, F., \& Mengiste, T. (2008). Tomato protein kinase $1 \mathrm{~b}$ mediates signaling of plant responses to necrotrophic fungi and insect herbivory. The Plant Cell, 20, 1964 1983. https://doi.org/10.1105/tpc.108.059477

Ali, F., Pan, Q., Chen, G., Zahid, K., \& Yan, J. (2013). Evidence of multiple disease resistance (MDR) and implication of meta-analysis in marker assisted selection. Plos One, 8, e68150. https://doi.org/10. 1371/journal.pone.0068150

Arcade, A., Labourdette, A., Falque, M., Mangin, B., Chardon, F., Charcosset, A., \& Joets, J. (2004). BioMercator: Integrating genetic maps and QTL towards discovery of candidate genes. Bioinformatics, 20, 2324-2326. https://doi.org/10.1093/BIOINFORMATICS/BTH230

Babu, P., Baranwal, D. K., Harikrishna, P. D., Bharti, H., Joshi, P., Thiyagarajan, B., Gaikwad, K. B., Bhardwaj, S. C., Singh, G. P., \& Singh, A. (2020). Application of genomics tools in wheat breeding to attain durable rust resistance. Frontiers in Plant Science, 11, 567147. https://doi.org/10.3389/fpls.2020.567147

Bhawar, K. B., Vinod, Sharma, J., Singh, A., Sivasamy, M., Singh, M., Prabhu, K., Tomar, S., Sharma, T., \& Singh, B. (2011). Molecular marker assisted pyramiding of leaf rust resistance genes Lr19 and Lr28 in wheat variety HD2687. Indian Journal of Genetics and Plant Breeding, 71, 304-311.

Bolton, M., Kolmer, J., Xu, W., \& Garvin, D. F. (2008). Lr34mediated leaf rust resistance in wheat: Transcript profiling reveals a high energetic demand supported by transient recruitment of multiple metabolic pathways. Molecular Plant-Microbe Interactions, 12, 1515-1527. https://doi.org/10.1094/MPMI-21-12-1515

Borrill, P., Ramirez-Gonzalez, R., \& Uauy, C. (2016). expVIP: A customizable RNA-seq data analysis and visualization platform. Plant Physiology, 170, 2172-2186. https://doi.org/10.1104/pp.15. 01667
Brown, J. K. M., \& Hovmøller, M. S. (2002). Aerial dispersal of pathogens on the global and continental scales and its impact on plant disease. Science, 297, 537-541. https://doi.org/10.1126/SCIENCE. 1072678

Carrijo, D., Lundy, M., \& Linquist, B. (2017). Rice yields and water use under alternate wetting and drying irrigation: A meta-analysis. Field Crops Research, 203, 173-180. https://doi.org/10.1016/J.FCR.2016. 12.002

Castro, A. J., Capettini, F., Corey, A. E., Filichkin, T., Hayes, P. M., Kleinhofs, A., Kudrna, D., Richardson, K., Sandoval-Islas, S., Rossi, C., \& Vivar, H. (2003a). Mapping and pyramiding of qualitative and quantitative resistance to stripe rust in barley. Theoretical and Applied Genetics, 107, 922-930. https://doi.org/10.1007/s00122-003-1329-6

Castro, A. J., Chen, X. M., Hayes, P. M., \& Johnston, M. (2003b). Pyramiding quantitative trait locus (QTL) alleles determining resistance to barley stripe rust: Effects on resistance at the seedling stage. Crop Science, 43, 651-659. https://doi.org/10.2135/CROPSCI2003.2234

Cavanagh, C. R., Chao, S., Wang, S., Huang, B. E., Stephen, S., Kiani, S., Forrest, K., Saintenac, C., Brown-Guedira, G. L., Akhunova, A., See, D., Bai, G., Pumphrey, M., Tomar, L., Wong, D., Kong, S., Reynolds, M., da Silva, M. L., Bockelman, H., ... Akhunov, E. (2013). Genomewide comparative diversity uncovers multiple targets of selection for improvement in hexaploid wheat landraces and cultivars. Proceedings of the National Academy of Science, 110, 8057-8062. https://doi.org/ 10.1073/pnas.1217133110

Chardon, F., Virlon, B., Moreau, L., Falque, M., Joets, J., Decousset, L., Murigneux, A., \& Charcosset, A. (2004). Genetic architecture of flowering time in maize as inferred from quantitative trait loci metaanalysis and synteny conservation with the rice genome. Genetics, 168, 2169-2185. https://doi.org/10.1534/GENETICS.104.032375

Chen, X., \& Kang, Z. (2017). Stripe rust. Springer.

Darvasi, A., \& Soller, M. (1997). A simple method to calculate resolving power and confidence interval of QTL map location. Behavior Genetics, 27, 125-132. https://doi.org/10.1023/A:1025685324830

Dobón, A., Bunting, D. C., Cabrera-Quio, L. E., Uauy, C., \& Saunders, D. (2016). The host-pathogen interaction between wheat and yellow rust induces temporally coordinated waves of gene expression. BMC Genomics, 17, 380. https://doi.org/10.1186/s12864-016-2684-4

Doerge, R. W. (2002). Mapping and analysis of quantitative trait loci in experimental populations. Nature Reviews Genetics, 3, 43-52. https: //doi.org/10.1038/nrg703

Drijepondt, S. C., \& Pretorius, Z. A. (1989). Greenhouse evaluation of adult-plant resistance conferred by the gene $L r 34$ to leaf rust of wheat. Plant Disease, 73, 669-671. https://doi.org/10.1094/PD-73-0669

Fatima, F., McCallum, B., Pozniak, C., Hiebert, C. W., McCartney, C., Fedak, G., You, F., \& Cloutier, S. (2020). Identification of new leaf rust resistance loci in wheat and wild relatives by array-based SNP genotyping and association genetics. Frontiers in Plant Science, 11, 583738. https://doi.org/10.3389/fpls.2020.583738

Feuillet, C., Penger, A., Gellner, K., Mast, A., \& Keller, B. (2001). Molecular evolution of receptor like kinase genes in hexaploid wheat. Independent evolution of orthologs after polyploidization and mechanisms of local rearrangements at paralogous loci. Plant Physiology, 125. 1304-1313. https://doi.org/10.1104/PP.125.3.1304

Feuillet, C., Reuzeau, C., Kjellbom, P., \& Keller, B. (1998). Molecular characterization of a new type of receptor-like kinase (wlrk) gene family in wheat. Plant Molecular Biology, 37, 943-953. https: //doi.org/10.1023/A:1006062016593 
Feuillet, C., Schachermayr, G., \& Keller, B. (1997). Molecular cloning of a new receptor-like kinase gene encoded at the $\mathrm{Lr} 10$ disease resistance locus of wheat. Plant Journal, 11, 45-52. https://doi.org/10.1046/J. 1365-313X.1997.11010045.X

Figlan, S., Ntushelo, K., Mwadzingeni, L., Terefe, T., Tsilo, T., \& Shimelis, H. (2020). Breeding wheat for durable leaf rust resistance in southern Africa: Variability, distribution, current control strategies, challenges and future prospects. Frontiers in Plant Science, 11, 549. https://doi.org/10.3389/fpls.2020.00549

Fu, D., Uauy, C., Distelfeld, A., Blechl, A., Epstein, L., Chen, X., Sela, H., Fahima, T., \& Dubcovsky, J. (2009). A kinase-START gene confers temperature-dependent resistance to wheat stripe rust. Science, 323, 1357-1360. https://doi.org/10.1126/science.1166289

Garcia, A. V., Al-Yousif, M., \& Hirt, H. (2012). Role of AGC kinases in plant growth and stress responses. Cellular and Molecular Life Sciences, 69, 3259-3267. https://doi.org/10.1007/s00018-012-1093-3

Goffinet, B., \& Gerber, S. (2000). Quantitative trait loci: A metaanalysis. Genetics, 155, 463-473.

Griffiths, S., Simmonds, J., Leverington, M., Wang, Y., Fish, L., Sayers, L., Alibert, L., Orford, S., Wingen, L., Herry, L., Faure, S., Laurie, D., Bilham, L., \& Snape, J. (2009). Meta-QTL analysis of the genetic control of ear emergence in elite European winter wheat germplasm. Theoretical and Applied Genetics, 119, 383-395. https://doi.org/10. 1007/s00122-009-1046-X

Gu, J., Sun, J., Liu, N., Sun, X., Liu, C., Wu, L., Liu, G., Zeng, F., Hou, C., Han, S., Zhen, W., \& Wang, D. (2020). A novel cysteine-rich receptor-like kinase gene, $T a C R K 2$, contributes to leaf rust resistance in wheat. Molecular Plant Pathology, 21, 732-746. https://doi.org/10. 1111/mpp.12929

Guo, B., Sleper, D. A., Lu, P., Shannon, J. G., Nguyen, H. T., \& Arelli, P. R. (2006). QTL associated with resistance to soybean cyst nematode in soybean: Meta-analysis of QTL locations. Crop Science, 46, 595602. https://doi.org/10.2135/CROPSCI2005.04-0036-2

Hafeez, A. N., Arora, S., Ghosh, S., Gilbert, D., Bowden, R. L., Robert, L., \& Wulff, B. H. B. (2021). Creation and judicious application of a wheat resistance gene atlas. Molecular Plant, 14, 1053-1070. https: //doi.org/10.1016/j.molp.2021.05.014

Herrera-Foessel, S., Singh, R., Huerta-Espino, J., Rosewarne, G., Periyannan, S. K., Viccars, L., Calvo-Salazar, V., Lan, C., \& Lagudah, E. (2012). Lr68: A new gene conferring slow rusting resistance to leaf rust in wheat. Theoretical and Applied Genetics, 124, 14751486. https://doi.org/10.1007/s00122-012-1802-1

Hiebert, C. W., Thomas, J. B., McCallum, B. D., \& Somers, D. J. (2008). Genetic mapping of the wheat leaf rust resistance gene Lr60 (LrW2). Crop Science, 48, 1020-1026. https://doi.org/10.2135/ CROPSCI2007.08.0480

Huang, L., Brooks, S. A., Li, W., Fellers, J. P., Trick, H. N., \& Gill, B. S. (2003). Map-based cloning of leaf rust resistance gene $L r 21$ from the large and polyploid genome of bread wheat. Genetics, 164, 655-664.

The International Wheat Genome Sequencing Consortium, Appels, R., Eversole, K., Stein, N., Feuillet, C., Keller, B., Rogers, J., Pozniak, C. J., Choulet, F., Distelfeld, A., Poland, J., Ronen, G., Sharpe, A. G., Barad, O., Baruch, K., Keeble-Gagnère, G., Mascher, M., Ben-Zvi, G., Josselin, A.-A., ... Wang, L, (2018). Shifting the limits in wheat research and breeding using a fully annotated reference genome. Science, 361, eaar7191. https://doi.org/10.1126/science.aar7191

Johnson, R. (1981). Durable resistance: Definition of, genetic control, and attainment in plant breeding. Phytopathology, 71, 567-568. https: //doi.org/10.1094/PHYTO-71-567
Johnson, R. (1984). A critical analysis of durable resistance. Annual Review of Phytopathology, 22, 309-330. https://doi.org/10.1146/ ANNUREV.PY.22.090184.001521

Khan, M. H., Bukhari, A., Dar, Z. A., \& Rizvi, S. M. (2013). Status and strategies in breeding for rust resistance in wheat. Agricultural Sciences, 4, 292-301. https://doi.org/10.4236/AS.2013.46042

Kim, K., Cho, S., Kang, C., Kim, K., Choi, C., Son, J., Park, C., \& Mo, A. Y. (2020). Research advances in wheat breeding and genetics for stripe rust resistance. Korean Journal of Breeding, 52, 93-103. https: //doi.org/10.9787/kjbs.2020.52.2.93

Kolmer, J. A. (1996). Genetics of resistance to wheat leaf rust. Annual Review of Phytopathology, 34, 435-455. https://doi.org/10.1146/ ANNUREV.PHYTO.34.1.435

Kolmer, J. A. (2005). Tracking wheat rust on a continental scale. Current Opinion in Plant Biology, 8, 441-449. https://doi.org/10.1016/J.PBI. 2005.05.001

Kolmer, J. A., \& Oelke, L. M. (2006). Genetics of leaf rust resistance in the spring wheats 'Ivan' and 'Knudson'. Canadian Journal of Plant Pathology, 28, 223-229. https://doi.org/10.1080/ 07060660609507290

Kuchel, H., Fox, R., Reinheimer, J., Mosionek, L., Willey, N., Bariana, H., Jefferies S. (2007). The successful application of a marker-assisted wheat breeding strategy. Molecular Breeding, 20, 295-308. https:// doi.org/10.1007/s11032-007-9092-Z

Lan, C. X., Liang, S. S., Wang, Z. L., Yan, J., Zhang, Y., Xia, X. C., \& He, Z. H. (2009). Quantitative trait loci mapping for adultplant resistance to powdery mildew in Chinese wheat cultivar Bainong 64. Phytopathology, 99, 1121-1126. https://doi.org/10.1094/ PHYTO-99-10-112

Liang, S. S., Suenaga, K., He, Z. H., Wang, Z. L., Liu, H. Y., Wang, D. S., Singh, R. P., Sourdille, P., \& Xia, X. C. (2006). Quantitative trait loci mapping for adult-plant resistance to powdery mildew in bread wheat. Phytopathology, 96, 784-789. https://doi.org/10.1094/ PHYTO-96-0784

Liu, S., Hall, M. D., Griffey, C. A., \& McKendry, A. L. (2009). Meta-analysis of QTL associated with Fusarium head blight resistance in wheat. Crop Science, 49, 1955-1968. https://doi.org/10. 2135/CROPSCI2009.03.0115

Liu, Y., Salsman, E., Wang, R., Galagedara, N., Zhang, Q., Fiedler, J. D., Liu, Z., Xu, S., Faris, J., \& Li, X. (2020). Meta-QTL analysis of tan spot resistance in wheat. Theoretical and Applied Genetics, 133, 2363-2375. https://doi.org/10.1007/s00122-020-03604-1

Löffler, M., Schön, C. C., \& Miedaner, T. (2009). Revealing the genetic architecture of FHB resistance in hexaploid wheat (Triticum aestivum L.) by QTL meta-analysis. Molecular Breeding, 23, 473-488. https: //doi.org/10.1007/s11032-008-9250-y

Lu, Y., Bowden, R., Zhang, G., Xu, X., Fritz, A., \& Bai, G. (2017). Quantitative trait loci for slow-rusting resistance to leaf rust in doubled-haploid wheat population CI13227 $\times$ Lakin. Phytopathology, 11, 1372-1380. https://doi.org/10.1094/PHYTO-09-160347-R

Maccaferri, M., Zhang, J., Bulli, P., Abate, Z., Chao, S., Cantu, D., Bossolini, E., Chen, X., Pumphrey, M., \& Dubcovsky, J. (2015). A genome-wide association study of resistance to stripe rust (Puccinia striiformis f. sp. tritici) in a worldwide collection of hexaploid spring wheat (Triticum aestivum L.). G3 Genes|Genomes|Genetics, 5, 449465. https://doi.org/10.1534/g3.114.014563

McFadden, E. S. (1930). A successful transfer of emmer characters to vulgare wheat. Journal of the American Society of Agronomy, 
22, 1020-1034 https://doi.org/10.2134/agronj1930.000219620022 $00120005 \mathrm{x}$

McIntosh, R. A. (1992). Close genetic linkage of genes conferring adult plant resistance to leaf rust and stripe rust in wheat. Plant Pathology, 41, 523-527. https://doi.org/10.1111/J.1365-3059.1992.TB02450.X

McIntosh, R. A., Wellings, C. R., \& Park, R. F. (1995). Wheat rusts: An atlas of resistance genes. CSIRO Publishing. https://doi.org/10.1071/ 9780643101463

Qi, Z., Sun, Y., Wu, Q., Liu, C., Hu, G., \& Chen, Q. (2017). A meta-analysis of seed protein concentration QTL in soybean. Canadian Journal of Plant Science, 91, 221-230. https://doi.org/10.4141/ cjps09193

Ramírez-González, R. H., Borrill, P., Lang, D., Harrington, S. A., Brinton, J., Venturini, L., Davey, M., Jacobs, J., van Ex, F., Pasha, A., Khedikar, Y., Robinson, S. J., Cory, A. T., Florio, T., Concia, L., Juery, C., Schoonbeek, H., Steuernagel, B., Xiang, D., ... Uauy, C. (2018). The transcriptional landscape of hexaploid wheat across tissues and cultivars. Science, 361, eaar6089. https://doi.org/10.1126/ science.aar6089

Ren, Y., Li, Z., He, Z., Wu, L., Bai, B., Lan, C., Wang, C., Zhou, G., Zhu, H., \& Xia, X. (2012). QTL mapping of adult-plant resistances to stripe rust and leaf rust in Chinese wheat cultivar Bainong 64. Theoretical and Applied Genetics, 125, 1253-1262. https: //doi.org/10.1007/s00122-012-1910-y

Rentel, M. C., Lecourieux, D., Ouaked, F., Usher, S. L., Petersen, L., Okamoto, H., Knight, H., Peck, S. C., Grierson, C. S., Hirt, H., \& Knight, M. R. (2004). OXI1 kinase is necessary for oxidative burstmediated signaling in Arabidopsis. Nature, 427, 858-861. https://doi. org/10.1038/nature02353

Richardson, K. L., Vales, M. I., Kling, J. G., Mundt, C. C., \& Hayes, P. M. (2006). Pyramiding and dissecting disease resistance QTL to barley stripe rust. Theoretical and Applied Genetics, 113, 485-495. https://doi.org/10.1007/s00122-006-0314-2

Rong, J., Feltus, F. A., Waghmare, V. N., Pierce, G. J., Chee, P. W., Draye, X., Saranga, Y., Wright, R. J., Wilkins, T. A., May, O. L., Smith, C. W., Gannaway, J. R., Wendel, J. F., \& Paterson, A. H. (2007). Meta-analysis of polyploid cotton QTL shows unequal contributions of subgenomes to a complex network of genes and gene clusters implicated in lint fiber development. Genetics, 176, $2577-$ 2588. https://doi.org/10.1534/genetics.107.074518

Rudd, J., Kanyuka, K., Hassani-Pak, K., Derbyshire, M., Andongabo, A., Devonshire, J., Lysenko, A., Saqi, M., Desai, N. M., Powers, S. J., Hooper, J., Ambroso, L., Bharti, A., Farmer, A., Hammond-Kosack, K. E., Dietrich, R. A., \& Courbot, M. (2015). Transcriptome and metabolite profiling of the infection cycle of Zymoseptoria tritici on wheat reveals a biphasic interaction with plant immunity involving differential pathogen chromosomal contributions and a variation on the hemibiotrophic lifestyle definition. Plant Physiology, 167, 11581185. https://doi.org/10.1104/pp.114.255927

Saintenac, C., Jiang, D., Wang, S., \& Akhunov, E. (2013). Sequence based mapping of the polyploid wheat genome. G3 Genes |Genomes|Genetics, 3, 1105-1114. https://doi.org/10.1534/g3.113. 005819

Singh, R. P. (1992). Genetic association of leaf rust resistance gene Lr34 with adult plant resistance to stripe rust in bread wheat. Phytopathology, 82, 835-838. https://doi.org/10.1094/PHYTO-82-835

Somers, J. D., Isaac, P., \& Edwards, K. (2004). A high-density microsatellite consensus map for bread wheat (Triticum aestivum L.).
Theoretical and Applied Genetics, 109, 1105-1114. https://doi.org/ 10.1007/s00122-004-1740-7

Soriano, J. M., \& Royo, C. (2015). Dissecting the genetic architecture of leaf rust resistance in wheat by QTL meta-analysis. Phytopathology, 105, 15851593. https://doi.org/10.1094/PHYTO-05-15-0130-R

Sosnowski, O., Charcosset, A., \& Joets, J. (2012). BioMercator V3: An upgrade of genetic map compilation and quantitative trait loci metaanalysis algorithms. Bioinformatics, 28, 2082-2083. https://doi.org/ 10.1093/bioinformatics/bts313

Toojinda, T., Baird, E., Booth, A., Broers, L., Hayes, P., Powell, W., Thomas, W., Vivar, H., \& Young, G. (1998). Introgression of quantitative trait loci (QTLs) determining stripe rust resistance in barley: An example of marker-assisted line development. Theoretical and Applied Genetics, 96, 123-131. https://doi.org/10.1007/ s001220050718

Toojinda, T., Baird, E., Broers, L., Chen, X. M., Hayes, P. M., Kleinhofs, A., Korte, J., Kudrna, D., Leung, H., Line, R. F., Powell, W., \& Vivar, H. (2000). Mapping quantitative and qualitative disease resistance genes in a doubled haploid population of barley. Theoretical and Applied Genetics, 101, 580-589. https://doi.org/10.1007/ s001220051519

Venske, E., dos Santos, R. S., da Rosa Farias, D., Rother, V., Maia, L. C., Pegoraro, C., \& Costa De Oliveira, A. (2019). Meta-analysis of the QTLome of Fusarium head blight resistance in bread wheat: Refining the current puzzle. Frontiers in Plant Science, 10, 727. https://doi.org/ 10.3389/fpls.2019.00727

Veyrieras, J. B., Goffinet, B., \& Charcosset, A. (2007). MetaQTL: A package of new computational methods for the meta-analysis of QTL mapping experiments. BMC Bioinformatics, 8, 49. https://doi.org/10. 1186/1471-2105-8-49

Walter, S., Brennan, J. M., Arunachalam, C., Ansari, K. I., Hu, X., Khan, M. R., Trognitz, F., Trognitz, B., Leonard, G., Egan, D., \& Doohan, F. M. (2008). Components of the gene network associated with genotype-dependent response of wheat to the Fusarium mycotoxin deoxynivalenol. Functional \& Integrative Genomics, 8, 421427. https://doi.org/10.1007/s10142-008-0089-4

Wang, M., Wang, S., \& Xia, G. (2015). From genome to gene: A new epoch for wheat research? Trends in Plant Science, 20, 380-387. https: //doi.org/10.1016/j.tplants.2015.03.010

Wang, R., Liu, Y., Isham, K., Zhao, W., Wheeler, J., Klassen, N., Hu, Y., Bonman, J. M., \& Chen, J. (2018). QTL identification and KASP marker development for productive tiller and fertile spikelet numbers in two high-yielding hard white spring wheat cultivars. Molecular Breeding, 38, 135. https://doi.org/10.1007/s11032-018-0894-y

Wang, S., Wong, D., Forrest, K., Allen, A., Chao, S., Huang, B. E., Maccaferri, M., Salvi, S., Milner, S. G., Cattivelli, L., Mastrangelo, A. M., Whan, A., Stephen, S., Barker, G., Wieseke, R., Plieske, J., Lillemo, M., Mather, D., Appels, R., ... Akhunov, E. (2014). Characterization of polyploid wheat genomic diversity using a high-density 90000 single nucleotide polymorphism array. Plant Biotechnology Journal, 12, 787-796. https://doi.org/10.1111/pbi.12183

Wang, Y., Xu, J., Deng, D., Ding, H., Bian, Y., Yin, Z., Wu, Y., Zhou, B., \& Zhao, Y. (2016). A comprehensive meta-analysis of plant morphology, yield, stay-green, and virus disease resistance QTL in maize (Zea mays L.). Planta, 243,459-471. https://doi.org/10.1007/ s00425-015-2419-9

Wang, Z. L., Li, L. H., He, Z. H., Duan, X. Y., Zhou, Y. L., Chen, X. M., Lillemo, M., Singh, R. P., Wang, H., \& Xia, X. C. (2005). 
Seeding and adult-plant resistance to powdery mildew in Chinese bread wheat cultivars and lines. Plant Disease, 89, 457-463. https: //doi.org/10.1094/PD-89-0457

Wiesner-Hanks, T., \& Nelson, R. (2016). Multiple disease resistance in plants. Annual Review of Phytopathology, 54, 229-252. https://doi. org/10.1146/annurev-phyto-080615-100037

William, M., Singh, R., Huerta-Espino, J., Islas, S. O., \& Hoisington, D. (2003). Molecular marker mapping of leaf rust resistance gene $l r 46$ and its association with stripe rust resistance gene $y r 29$ in wheat. Phytopathology, 2, 153-159. https://doi.org/10.1094/PHYTO.2003.93.2. 153

Wu, Y., Huang, M., Tao, X., Guo, T., Chen, Z., \& Xiao, W. (2016). Quantitative trait loci identification and meta-analysis for rice paniclerelated traits. Molecular Genetics and Genomics, 291, 1927-1940. https://doi.org/10.1007/s00438-016-1227-7

Xiang, K., Reid, L., Zhang, Z., Zhu, X., \& Pan, G. (2012). Characterization of correlation between grain moisture and ear rot resistance in maize by QTL meta-analysis. Euphytica, 183, 185-195. https: //doi.org/10.1007/s10681-011-0440-Z

Xin, F., Zhu, T., Wei, S., Han, Y., Zhao, Y., Zhang, D., Ma, L., \& Ding, Q. (2020). QTL mapping of kernel traits and validation of a major QTL for kernel length-width ratio using SNP and bulked segregant analysis in wheat. Scientific Reports, 10, 25. https://doi.org/10.1038/ s41598-019-56979-7

Yang, L., Xie, C., Li, W., Ruijie, Z., Dengwei, J., \& Qing, Y. (2013). Expression of a wild eggplant ribosomal protein L13a in potato enhances resistance to Verticillium dahliae. Plant Cell, Tissue and Organ Culture, 115, 329-340. https://doi.org/10.1007/ s11240-013-0365-4

Yu, L., Barbier, H., Rouse, M., Singh, S., Singh, R. Bhavani, S., HuertaEspino, J., \& Sorrells, M. (2014). A consensus map for Ug99 stem rust resistance loci in wheat. Theoretical and Applied Genetics, 127, 1561-1581. https://doi.org/10.1007/s00122-014-2326-7

Zhang, H., Yang, Y., Wang, C., Liu, M., Li, H., Fu, Y., Wang, Y., Nie, Y., Liu, X., \& Ji, W. (2014). Large-scale transcriptome comparison reveals distinct gene activations in wheat responding to stripe rust and powdery mildew. BMC Genomics, 15, 898. https://doi.org/10.1186/ 1471-2164-15-898

Zheng, T., Hua, C., Li, L., Sun, Z., Yuan, M., Bai, G., Humphreys, G. D., \& Tao, L., (2020). Integration of meta-QTL discovery with omics: Towards a molecular breeding platform for improving wheat resistance to Fusarium head blight. Crop Journal, 9, 739-749. https: //doi.org/10.1016/j.cj.2020.10.006

Zhu, A., Ibrahim, J., \& Love, M. (2019). Heavy-tailed prior distributions for sequence count data: Removing the noise and preserving large differences. Bioinformatics, 35, 2084-2092. https://doi.org/10.1093/ bioinformatics/bty895

\section{SUPPORTING INFORMATION}

Additional supporting information may be found in the online version of the article at the publisher's website.

How to cite this article: Amo, Aduragbemi, \& Soriano, Jose Miguel. (2021). Unravelling consensus genomic regions conferring leaf rust resistance in wheat via meta-QTL analysis. Plant Genome. e20185. https://doi.org/10.1002/tpg2.20185 